\title{
Expression Profiling of Long Noncoding RNA Splice Variants in Human Microvascular Endothelial Cells: Lipopolysaccharide Effects In Vitro
}

\author{
Imran H. Chowdhury, ${ }^{1}$ Hema P. Narra, ${ }^{1,2}$ Abha Sahni, ${ }^{1,2}$ Kamil Khanipov, ${ }^{3}$ \\ Casey L. C. Schroeder, ${ }^{1}$ Jignesh Patel, ${ }^{1}$ Yuriy Fofanov, ${ }^{3}$ and Sanjeev K. Sahni ${ }^{1,2}$ \\ ${ }^{1}$ Department of Pathology, University of Texas Medical Branch, 301 University Boulevard, Galveston, TX 77555, USA \\ ${ }^{2}$ Institute for Human Infections and Immunity, University of Texas Medical Branch, Galveston, TX, USA \\ ${ }^{3}$ Department of Pharmacology, University of Texas Medical Branch, Galveston, TX, USA \\ Correspondence should be addressed to Sanjeev K. Sahni; sksahni@utmb.edu
}

Received 21 May 2017; Accepted 22 August 2017; Published 25 September 2017

Academic Editor: Anshu Agrawal

Copyright (c) 2017 Imran H. Chowdhury et al. This is an open access article distributed under the Creative Commons Attribution License, which permits unrestricted use, distribution, and reproduction in any medium, provided the original work is properly cited.

Endothelial cell interactions with lipopolysaccharide (LPS) involve both activating and repressing signals resulting in pronounced alterations in their transcriptome and proteome. Noncoding RNAs are now appreciated as posttranscriptional and translational regulators of cellular signaling and responses, but their expression status and roles during endothelial interactions with LPS are not well understood. We report on the expression profile of long noncoding (lnc) RNAs of human microvascular endothelial cells in response to LPS. We have identified a total of 10,781 and $8310 \operatorname{lncRNA}$ transcripts displaying either positive or negative regulation of expression, respectively, at 3 and $24 \mathrm{~h}$ posttreatment. A majority of LPS-induced lncRNAs are multiexonic and distributed across the genome as evidenced by their presence on all chromosomes. Present among these are a total of 44 lncRNAs with known regulatory functions, of which 41 multiexonic lncRNAs have multiple splice variants. We have further validated splice variant-specific expression of EGO (NONHSAT087634) and HOTAIRM1 (NONHSAT119666) at $3 \mathrm{~h}$ and significant upregulation of lnc-IL7R at $24 \mathrm{~h}$. This study illustrates the genome-wide regulation of endothelial lncRNA splice variants in response to LPS and provides a foundation for further investigations of differentially expressed lncRNA transcripts in endothelial responses to LPS and pathophysiology of sepsis/septic shock.

\section{Introduction}

Uncontrolled systemic inflammation caused by sepsis is one of the leading causes of death and disability throughout the world $[1,2]$. Sepsis is defined as a systemic inflammatory response syndrome due to its ability to involve multiple organ systems distant from the site(s) of infection $[1,3]$. Exposure of endothelial cells to lipopolysaccharide (LPS) in the cell wall of Gram-negative bacteria plays a central role in the pathophysiology of sepsis [1]. The single, continuous layer of endothelial cells lining the microcirculation constitutes an intricate organ responsible for maintaining an antiadhesive and antithrombotic surface along the blood vessels and regulation of blood flow and vasomotor tone.
Interactions between microvascular endothelium and blood-borne endotoxins such as LPS and inflammatory cytokines such as interferon- $\gamma$ result in the shedding of endothelial glycocalyx, increased expression of inflammatory markers (intercellular adhesion molecule-1, vascular cell adhesion molecule-1 (VCAM-1), and interleukin-6 (IL-6)), disruption of gap junctions, and increased vascular permeability $[4,5]$.

The human genome harbors a large number of sequences coding for RNAs that are not translated but implement regulatory effects on myriad cellular functions. It is rather intriguing that although a majority of the genome is transcribed, a very small fraction of only $2 \%$ encodes for the proteins and the rest gives rise to thousands of noncoding 
RNAs (ncRNAs) lacking protein-coding capacity [6]. In recent years, it has become increasingly evident that ncRNAs are involved in diverse major biological processes, including immune regulation, cell cycle, apoptosis, posttranscriptional and translational regulation, epigenetic modification, and nuclear genome organization [7-11]. ncRNAs are broadly classified into short ncRNAs of $<200$ nucleotides and long noncoding RNAs (lncRNAs) of lengths varying from $>200$ nucleotides to tens of kilobases [12]. IncRNAs are highly versatile molecules that can bind to other RNA templates, DNA, and a vast repertoire of proteins, highlighting their regulatory potential in the determination of pathophysiology of various human ailments, including Alzheimer's disease, cardiovascular disease, and cancer [13-16].

The innate immune recognition of bacterial products is orchestrated by a family of transmembrane receptors known as Toll-like receptors (TLRs) [17]. Endothelial cells are known to express a number of TLRs, including TLR4, and display an activated phenotype mediated by a receptor complex consisting of TLR4, cluster of differentiation 14 (CD14), and myeloid differentiation protein-2 (MD-2) in response to LPS [1]. The early, immediate response is governed by the recruitment of myeloid differentiation factor 88 (MyD88), an adaptor protein which initiates a MyD88dependent pathway culminating in the early activation of nuclear factor-kappaB (NF- $\kappa \mathrm{B})$ and mitogen-activated protein kinase (MAPK) pathways. Parallel activation of a MyD88-independent pathway results in the late-phase activation of NF- $\kappa$ B [18]. Published evidence also documents the ability of LPS to trigger both apoptosis and expression of anti-apoptotic proteins in endothelial cells [19]. Since the activation of endothelial cell signaling and injury by LPS plays a major role in the pathogenesis of bacterial sepsis and septic shock, the molecular mechanisms underlying endothelial responses to LPS have been investigated extensively [20-22]. However, with the exception of a recently published study [22], the regulatory roles of lncRNAs as potential contributors to endothelial cell responses to LPS and determinants of pathophysiological mechanisms of sepsis have not yet been explored in much detail. Moreover, lncRNAs exhibit distinct patterns of expression in different cell types, necessitating the identification and characterization of transcript variants of lncRNAs responsible for the pathogenesis of sepsis syndrome. In an attempt to address this important knowledge gap, we have investigated the cumulative lncRNA signature of microvascular endothelium treated in vitro with LPS. Our results not only suggest robust changes in the lncRNA transcriptome of endothelial cells treated with LPS but also reveal differential expression of selective splice variants of $\operatorname{lncRNAs}$ with known function(s).

\section{Materials and Methods}

2.1. Cell Culture, LPS Treatment, and RNA Isolation. Human dermal microvascular endothelial cells (HMECs) obtained from the Centers for Disease Control and Prevention (Atlanta, GA) were grown in MCDB 131 medium (Caisson's Laboratories) containing 10\% fetal bovine serum (Aleken Biologicals), $10 \mathrm{ng} / \mathrm{ml}$ epidermal growth factor (Thermo
Fisher Scientific), $1 \mu \mathrm{g} / \mathrm{ml}$ hydrocortisone (Sigma), and $10 \mathrm{mM}$ L-glutamine (Thermo Fisher Scientific) [23]. LPS from Escherichia coli (E. coli O111: B4; Invivogen) was dissolved in sterile water and prepared fresh at the time of use. At approximately $90 \%$ confluence in culture, HMECs were treated with LPS $(1 \mu \mathrm{g} / \mathrm{ml})$ for 3 and $24 \mathrm{~h}$. HMECs were used at passage numbers 22 to 25 and routinely tested for mycoplasma contamination at the Tissue Culture Core Facility at the University of Texas Medical Branch (UTMB). RNA-Seq was performed on two independent mock-treated controls and LPS-treated samples ( 3 and $24 \mathrm{~h}$ ). Total RNA was isolated by the Tri-Reagent method (Invitrogen) following a combination of the manufacturer's instructions and our previously optimized procedures $[24,25]$. Total RNA was treated with DNaseI (NEB) to remove any genomic DNA contamination. The quality of RNA preparations was verified on a bioanalyzer (Agilent Technologies), and samples with an RNA integrity number (RIN) of $>9.0$ were used for further analysis.

2.2. RNA Sequencing. Total RNA was enriched using a Ribo-Zero rRNA Removal kit (Illumina). cDNA libraries were constructed from enriched total RNA, and RNA-Seq was performed on an Illumina HiSeq $1500^{\circledR}$ system at the Molecular Genomics and Sequencing Core facility of the UTMB as 150 base single-end reads. The filtration of resultant reads was performed to ensure inclusion of only high quality sequences in the downstream analysis. The process of filtration included removal of reads containing nucleotide sequences below the quality threshold of 0.05 (using modified the Richard Mott algorithm), unknown nucleotides, and adapters used in the generation of sequencing libraries. The high quality reads thus obtained were trimmed by 15 bases from the 5 ' end to reduce nucleotide bias from their origin. All high-quality reads retained after trimming were mapped to Homo sapiens RefSeq coding genes (GRch37/hg19) using CLC Genomics Workbench 9.0.1 (http://www.clcbio.com), and the reads mapping to known protein-coding genes (PCGs) were excluded from further analysis. Finally, the remaining reads, which did not map to the protein-coding transcriptome, were mapped to the human ncRNA database (NONCODE_V4; www.noncode.org) [26] to identify differentially expressed ncRNAs in reponse to LPS treatment. Mapping to both RefSeq genes and ncRNAs was performed allowing up to 9 base mismatches $(94.4 \%$ identity) as determined by global alignment scoring. Samples were grouped according to their designation as either control (mock treated) or treated (LPS treatment). The RNA-Seq data was further analyzed and normalized by calculating reads per kilobase million (RKPM) for each transcript using the formula below [27].

$$
\frac{\text { Total exon reads }}{\text { Mapped reads (millions) } \times \text { exon length }(\mathrm{KB})} \text {. }
$$

Finally, fold changes for PCGs and ncRNA transcripts (excluding short ncRNAs of $<200 \mathrm{bp}$ ) at 3 and $24 \mathrm{~h}$ posttreatment were determined using mock-treated controls as the baseline. 
TABLE 1: List of primer sequences used for qRT-PCR.

\begin{tabular}{lccc}
\hline lncRNA name & Primer name & Orientation & Sequence $\left(5^{\prime}-3^{\prime}\right)$ \\
\hline \multirow{2}{*}{ EGO (NONHSAT087634) } & EGO-F & Forward & ACCCCAAACGAAAACAAGATAGAC \\
& EGO-R & Reverse & CCCATGCTAGCCAGCCTTTA \\
HOTAIRM1 (NONHSAT119666) & HOTAIRM1-F & Forward & GAAAGATGAACTGGCGAGAGAAA \\
& HOTAIRM1-R & Reverse & AGCTCCTGGATGCGATTCG \\
lnc-IL7R & lnc-IL7R-F & Forward & CCAGCCTTTGCCTCTTCCTTCAAT \\
& lnc-IL7R-R & Reverse & CCGTACCAAGTCTCT TAGCCC CTC \\
\hline
\end{tabular}

2.3. Cataloging of $\operatorname{lncRNAs}$. Differentially expressed lncRNA transcripts in our RNA-Seq data were catalogued based on their chromosomal and strand origin according to NONCODE database (NONCODE_V4) and grouped based on their chromosomal location (Chr 1-22, Chr 23 (X and Y), and mitochondrial DNA) and origin of the strand (sense or antisense). All lncRNAs originating from $\mathrm{X}$ and $\mathrm{Y}$ alleles of chromosome 23 were merged together and named as XY. The length of differentially expressed lncRNA transcripts and their exon numbers were also captured from the NONCODE database. We grouped lncRNA transcripts based on their length into four categories of 200-500 bp, 501-2000 bp, 2001-5000 bp, and above 5000 bp. Similarly, differentially expressed lncRNA transcripts were categorized as uniexonic, biexonic, and multiexonic based on the exon numbers. Sequences of known $\operatorname{lncRNAs}$ with assigned function(s) were downloaded from $\ln \mathrm{RNAdb}$ (http://www.lncrnadb.org) [28] and blasted against the sequences for ncRNAs in the NONCODE database. We thus captured NONCODE IDs for known lncRNAs and also recorded all of their transcript variants from the NONCODE database. To further understand the expression profile of PCGs overlapping with the differentially expressed lncRNAs identified in this study, we segregated the lncRNA transcripts based on their genomic location. The expression of PCGs from the exonic or antisense lncRNA transcripts was determined based on RPKM values as described above. Finally, to compare our results to the expression profile of lncRNAs in HUVECs (human umbilical vein endothelial cells) during LPS treatment [22], we downloaded the sequences for differentially expressed lncRNAs in this study from LNCipedia (LNCipedia.org) and NCBI and performed BLAST analysis of these lncRNAs in the NONCODE database to obtain their corresponding NONCODE IDs.

2.4. Quantitative Real-Time PCR ( $q R T-P C R)$. SYBR greenbased quantitative polymerase chain reaction (qRT-PCR) assays were carried out for further validation of selected lncRNA transcripts from the RNA-Seq analysis on a StepOnePlus Real-time PCR System (Applied Biosystems). Briefly, DNaseI-treated RNA $(1 \mu \mathrm{g})$ was reverse transcribed using a cDNA synthesis kit (Applied Biosystems) and qPCR was performed using splice variant-specific primers designed using Primer Express 3.0.1 software (Applied Biosystems). The sequences of splice variant-specific primers and the schematics employed for their selection are presented in Table 1 and Figure 1. Full-length sequence alignments of
lncRNA transcript variants are presented in the Supplementary File. The PCR reactions were performed in triplicate, and the expression of transcripts normalized against the housekeeping gene $18 \mathrm{~S}$ rRNA. The level of expression and relative quantification were determined via calculations based on the $2^{-\Delta \mathrm{Ct}}\left[2^{(-\Delta \mathrm{Ct} \text { of treatment })} / 2^{(-\Delta \mathrm{Ct} \text { of control })}\right]$ method.

2.5. RefSeq Pathway Analysis. To identify differentially regulated protein-coding gene pathways in HMECs during LPS treatment, we mapped our RNA-Seq reads to the human RefSeq database (GRch37/hg19) following same parameters as described above for ncRNAs. PCGs showing $\geq 3$-fold up- or downregulation were further subjected to Ingenuity ${ }^{\circledR}$ Systems Pathway Analysis (IPA; Ingenuity Systems, Redwood City, CA, USA; http://www.ingenuity.com) to identify significantly regulated canonical pathways in endothelial cells during LPS treatment in direct comparison to the mock-treated controls. Only pathways exhibiting significant changes $(P \leq 0.05)$ were considered for the analysis.

2.6. Statistical Analysis. The D'Agostino and Pearson omnibus normality test was performed to test the normal distribution of data. Comparisons between the unmatched groups were done by the Mann-Whitney $U$ test. GraphPad Prism version 5 (GraphPad Software Inc., San Diego, California) was used for the statistical analysis. Statistical significance was accepted at the $P$ value of $\leq 0.05$.

\section{Results}

To catalogue alterations in the lncRNA expression profile of HMECs subjected to LPS treatment for $3 \mathrm{~h}$ and $24 \mathrm{~h}$, we first performed RNA sequencing. Sequencing produced approximately 28-37 million reads per library, of which nearly $31-$ $36 \%$ and $11-15 \%$ of the reads mapped to mRNAs and ncRNAs, respectively (Supplementary Table 1 available online at https://doi.org/10.1155/2017/3427461). Of the total RNA in eukaryotic cells, mRNAs and rRNAs represent approximately 5 and $80 \%$, respectively, whereas the remaining $15 \%$ includes other RNA molecules comprised of spliceosomal RNAs, snoRNAs, nonpolyadenylated RNAs, tRNAs, mitochondrial RNAs, and other specialized RNAs such as LINE/SINE or B-element RNAs which are abundantly expressed and mapped to the repeat regions of the genome [29]. Similar to the results observed in our RNA-Seq datasets, a recent study documents the mapping of about $30-60 \%$ of the reads to rRNAs despite the application of enrichment 
NONHSAT087636 NONHSAT087634 NONHSAT087635

NONHSAT087636 NONHSAT087634 NONHSAT087635

NONHSAT087636 NONHSAT087634 NONHSAT087635

NONHSAT087636 NONHSAT087634 NONHSAT087635

NONHSAT087636 NONHSAT087634 NONHSAT087635

NONHSAT119666 NONH SAT119667 NONHSAT119668 NONHSAT119664 NONHSAT119665

NONHSAT119666
NONHSAT119667
NONHSAT119668
NONHSAT119664
NONHSAT119665
NONHSAT119666
NONHSAT119667
NONHSAT119668
NONHSAT119664
NONHSAT119665
NONHSAT119666
NONHSAT119667
NONHSAT119668
NONHSAT119664
NONHSAT119665
NONHSAT119666
NONHSAT119667
NONHSAT119668
NONHSAT119664
NONHSAT119665
NONHSAT119666
NONHSAT119667
NONHSAT119668
NONHSAT119664
NONHSAT119665
NONHSAT119666
NONHSAT119667
NONHSAT119668
NONHSAT119664
NONHSAT119665

ATGCATTGTTATTAAAAAAAAATGTGCTTCCATTCCACTCCATTTTAAAGGTCTACCTTT ATCCAATGTGAGCAACTGAAAAGGTGCCATGT- - - - - - - ATTAGCTATTTGCCATT

AAAACTCATTGGCTAACCAAGCAGTGACTACTTCCTTCTCAGATCAAATAACCAGTGCAG A- - - - -TGGTTCTGCAAG -- -TG -- --CTCAGATGACTCATAAAATGACCAGAACAA $\longrightarrow$ CCTGTTCCCACCCCAAACGAAAACAAGATAGACACTGCTCTCTAGTAGGCAGAGCTCCAA

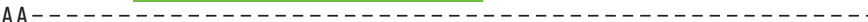
AGTGGGTACAGGGCACTGAATAGCTCCCTCACATTGTACTCATGTAACTTAAAGGCTGGC - - -

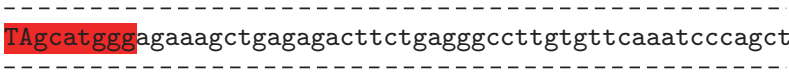

(a) NONHSAT087634

CCTCCGGGAGGTGGGGGCTGGGAGGCGTCCCCCGCTCCCGCCCCCTCCCCACCGTTCAAT СC

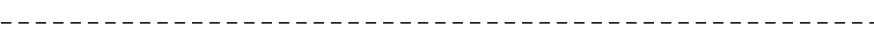
CCTCCGGGAGGTGGGGGCTGGGAGGCGTCCCCCGCTCCCGCCCCCTCCCCACCGTTCAAT CCTCCGGGAGGTGGGGGCTGGGAGGCGTCCCCCGCTCCCGCCCCCTCCCCACCGTTCAAT

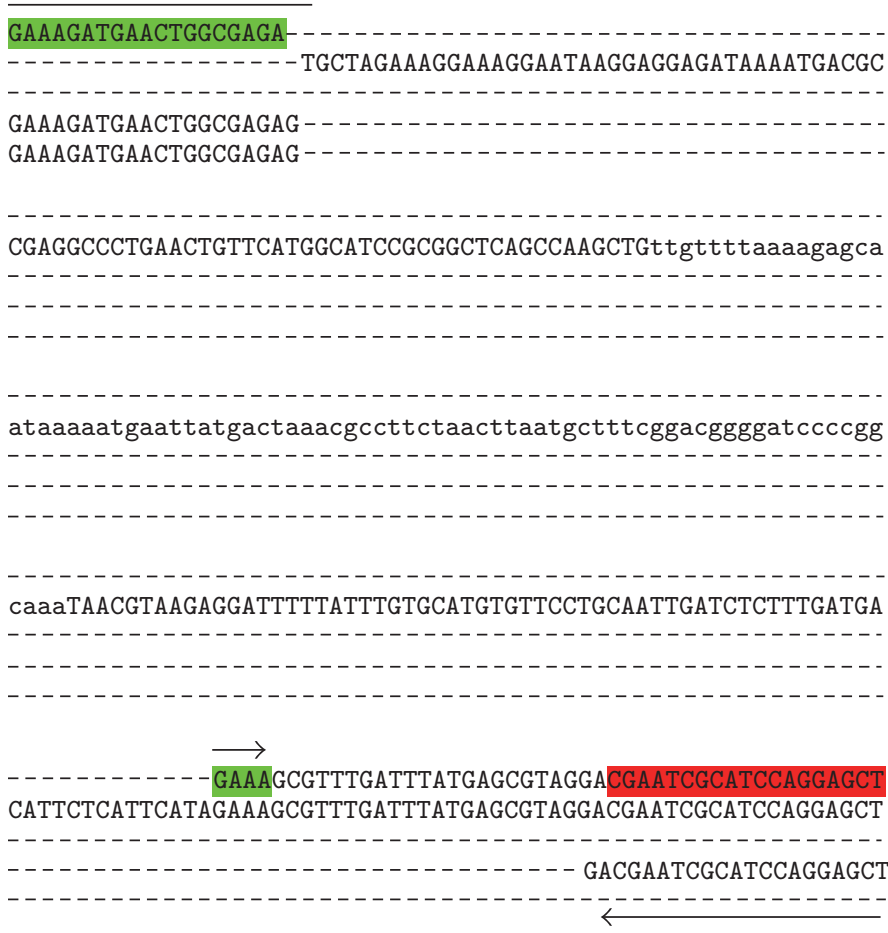

GCGCAGCCCTGGCCGCTGCCGGGACGCCCTGCTCCGCGCTGAGCTTGGGGCCAGAAACCA GCGCAGCCCTGGCCGCTGCCGGGACGCCCTGCTCCGCGCTGAGCTTGGGGCCAGAAACCA

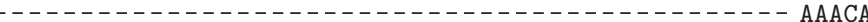
GCGCAGCCCTGGCCGCTGCCGGGACGCCCTGCTCCGCGCTGAGCTTGGGGCCAGAAACCA

(b) NONHSAT119666

Figure 1: Schematic of (a) NONHSAT087634 and (b) NONHSAT119666 splice variant specific primer selection.

procedures [30]. In the present study, we consistently achieved enrichment of mRNA and lncRNA reads following Ribo-Zero rRNA removal and any remaining reads mapping to rRNAs and tRNAs were not included in a downstream analysis. The total reads thus obtained (sans those originating from rRNAs and tRNAs) from untreated controls and LPS- treated HMECs were first mapped to the RefSeq genes of human genome (GRch37/hg19) to subtract the reads mapping to the protein-coding transcriptome. The remaining reads were then mapped to a total of 145,331 ncRNA transcripts annotated in the NONCODE database. Among these, we selected only the ncRNA transcripts clearly represented 


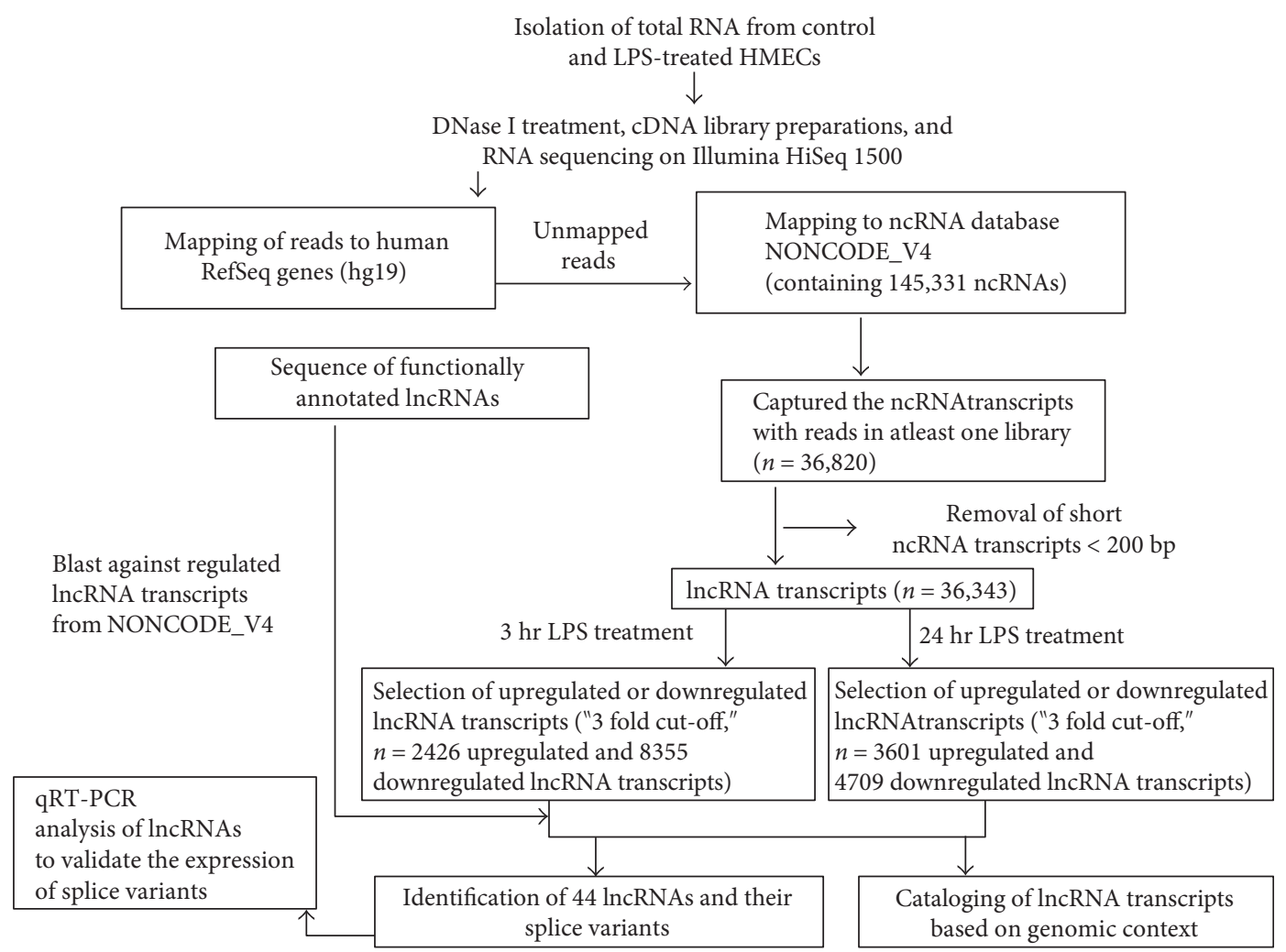

FIGURE 2: Schematic illustration of the procedure for identification, cataloging, and validation of lncRNA transcripts.

by a noticeable number of reads in at least one of our sample categories, that is, untreated and LPS-treated HMECs at $3 \mathrm{~h}$ and $24 \mathrm{~h}$, allowing us to narrow down the number of ncRNA transcripts to 36,820 . At this point, we only retained ncRNA transcripts with a length of $\geq 200 \mathrm{bp}$, leaving a total of 36,343 lncRNA transcripts in our dataset. The schematics employed for the deduction of IncRNA repertoire are presented in Figure 2. Further analysis of changes in the expression of lncRNAs using their basal levels in untreated HMECs (controls) allowed us to identify 2426 and $8355 \operatorname{lncRNAs}$ that were either up- or downregulated in LPS-treated HMECs at $3 \mathrm{~h}$. Through an identical analysis, a total of 3601 and 4709 lncRNAs were found to be either up- or downregulated at $24 \mathrm{~h}$.

Next, we focused our attention on differentially expressed lncRNAs ( $\geq 3$ fold) at 3 and $24 \mathrm{~h}$ following LPS treatment by determining their chromosomal location (Figure 3). Long noncoding RNAs modulated upwards and downwards due to LPS treatment were abundant and distributed throughout all the chromosomes. Also, a majority of upregulated lncRNAs at 3 and $24 \mathrm{~h}$ posttreatment were located on chromosomes 1, 10, 11, and 12 (Figures 3(a) and 3(c)). On the other hand, lncRNAs displaying downmodulation at $3 \mathrm{~h}$ were more or less evenly distributed across all chromosomes (Figure 3(b)) but originated predominantly from chromosomes $1,10,11$, and 12 at $24 \mathrm{~h}$ (Figure 3(d)). Figure 4 displays the distribution of lncRNAs in our test samples based on the strand of their origin, overall length, and exonic composition. At a glance, subsets of IncRNA-coding sequences undergoing changes in their expression following LPS treatment were almost evenly distributed on the positive (leading) and negative (lagging) strands of the genome (Figure 4(a)). Our results further suggest that nearly $58 \%$ of both up- and downregulated lncRNA transcripts range from 501-2000 bp, while there are relatively few transcripts of $>5001 \mathrm{bp}$ (Figure 4(b)). In regard to their genomic composition, about 25 to $30 \%$ differentially expressed lncRNA transcripts are uniexonic, while the remaining have two or more exons (Figure 4(c)).

Since very little is known about the functions of lncRNAs in the endothelium and our analysis revealed extensive modulation of their expression, we next focused our efforts on identifying those with a defined functional role in the determination of endothelial responses in vitro or in vivo. To accomplish this, sequences of functionally annotated lncRNAs were acquired from lncRNAdb [28] and blasted against the NONCODE database. Subsequent search of such lncRNAs in our datasets enabled us to capture a total of $44 \operatorname{lncRNAs}$ that were either up- or downregulated in LPS-treated HMECs at $3 \mathrm{~h}$ or $24 \mathrm{~h}$. The characteristic features of these lncRNAs, including their chromosomal location, the number of splice variants, and expression pattern, are detailed in Table 2 and Supplementary Table 2. Functionally, these lncRNAs are involved in the regulation of cell proliferation, growth, and migration; determination of immune responses, modulation of apoptosis, invasion, and metastasis; control of epigenetic modifications; and genomic imprinting (Figure 5). Intriguingly, a total of 41 lncRNAs (out of 44 identified through systematic analysis) have multiple splice variants and are multiexonic (Table 2 and Supplementary Table 2). We also observed differential expression of splice 


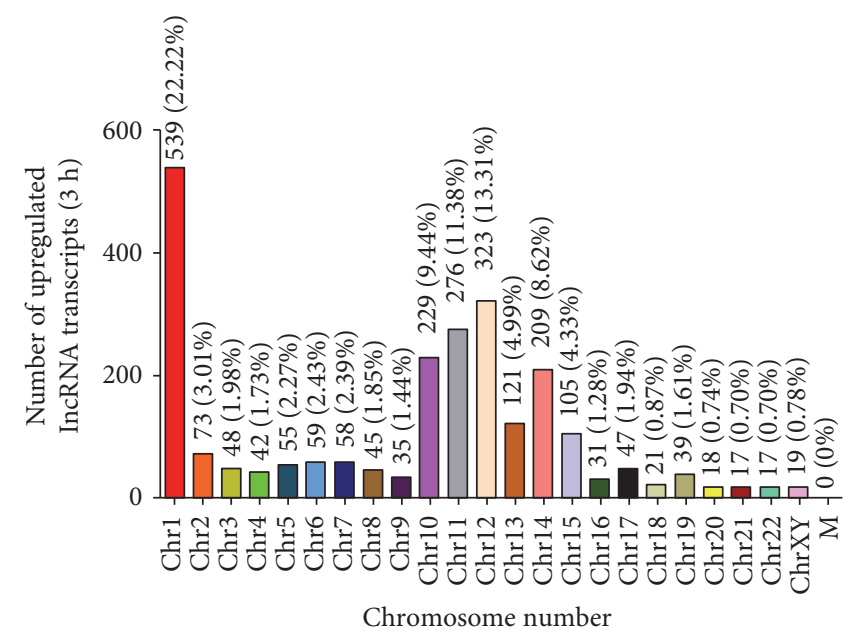

(a)

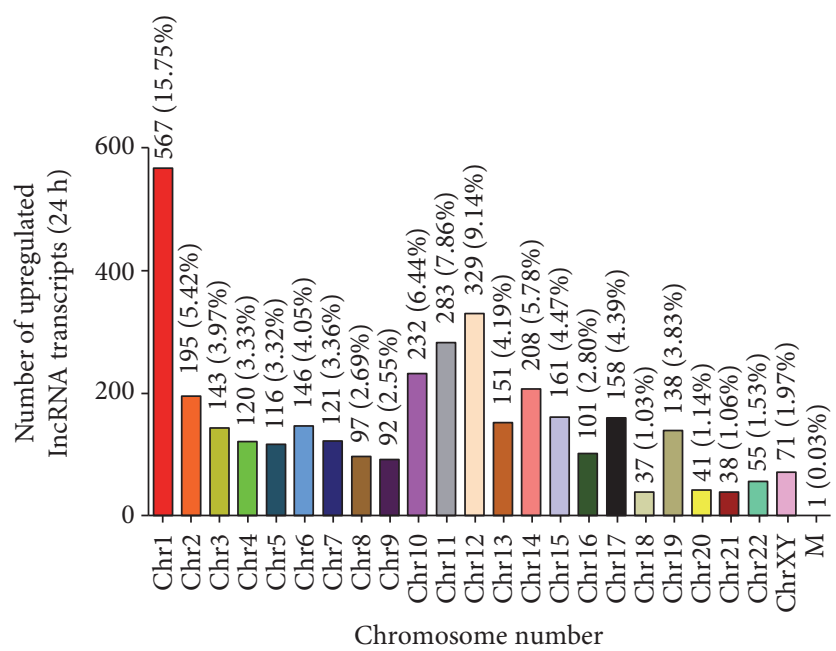

(c)

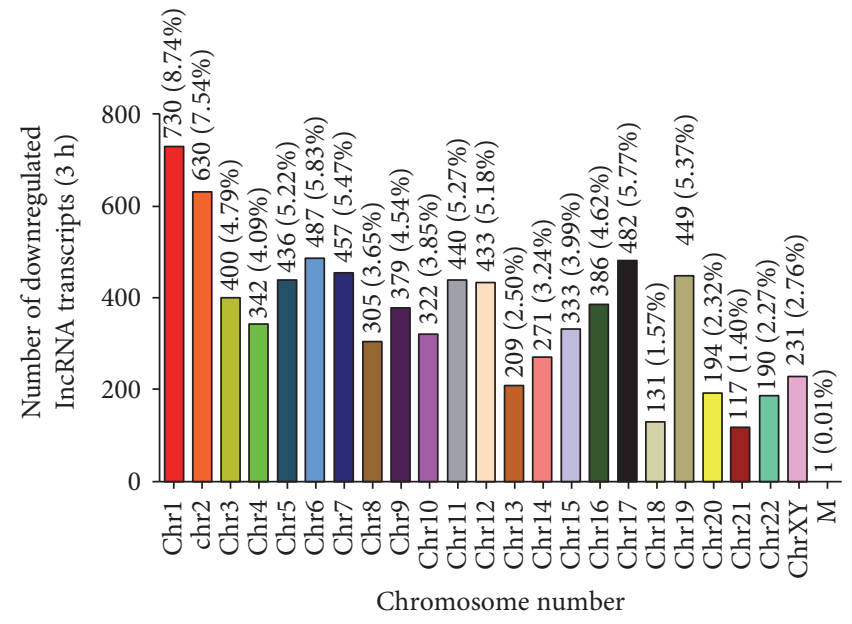

(b)

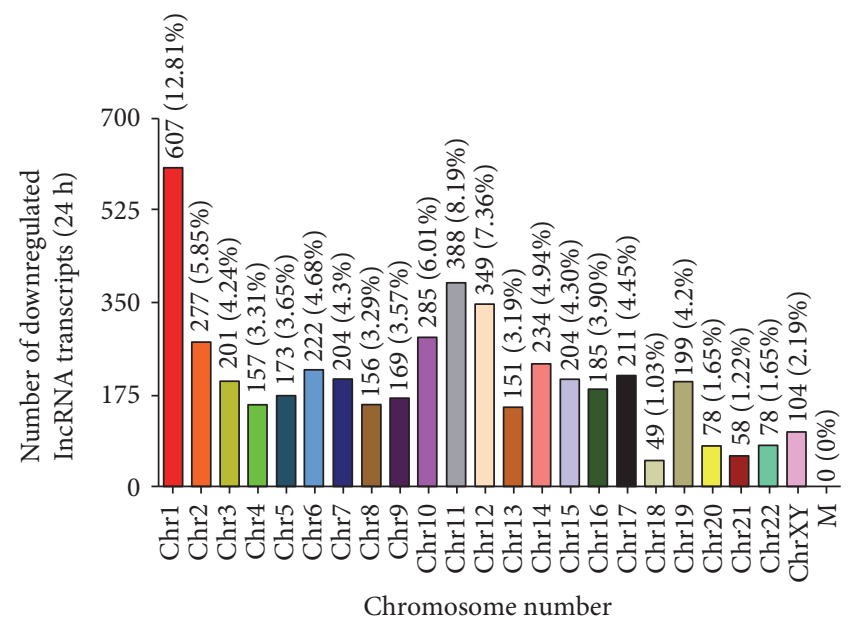

(d)

FIGURE 3: Chromosome-wise distribution of differentially expressed lncRNA transcripts in HMECs after LPS treatment. (a) Upregulated transcripts after $3 \mathrm{~h}$. (b) Downregulated transcripts after $3 \mathrm{~h}$. (c) Upregulated transcripts after $24 \mathrm{~h}$. (d) Downregulated transcripts after $24 \mathrm{~h}$.

variants belonging to the same lncRNA, suggesting selective modulation of the transcript variants after LPS treatment (Supplementary Table 2). Figure 6 shows the total number of splice variants available for 44 functionally annotated lncRNAs and the proportion of differentially expressed splice variants in HMECs after LPS treatment at 3 and 24h. A comparative analysis of our dataset with that of LPS-treated HUVECs in a recently published study [22] enabled the identification of 15 lncRNAs expressed in response to LPS treatment (Table 3). Among these, only one (NONHSAT140176) out of ten transcript variants of lncRNA AL132709.5 displayed higher expression at $24 \mathrm{~h}$. Similarly, only one of seven splice variants of lncRNA AC068282.3, namely, NONHSAT074153, also had higher expression at $24 \mathrm{~h}$ in comparison to its basal level in untreated controls. In contrast, both splice variants for CLDN10-AS1 (NONHSAT034761 and NONHSAT034762) were upregulated at $24 \mathrm{~h}$ in LPS-treated HMECs. Splice variants of CTC-459I6.1, RP11-138B4.1, and RP11-676J12.6 were not detectable in our datasets at both 3 and $24 \mathrm{~h}$ post-
LPS treatment. Interestingly, three of eight splice variants of BX284650.1 had no detectable expression, yet the remaining 5 transcript variants showed a variable (either up- or downregulation) pattern of expression in response to LPS. The expression of lncRNA XLOC_006311 (NONHSAT124447) exhibited downregulation at $24 \mathrm{~h}$ after LPS treatment. Thus, consistent with our findings, a similar analysis of the expression profile of lncRNAs differentially expressed in human umbilical vein endothelial cells (HUVECs) exposed to LPS also suggests that all splice variants belonging to the same lncRNA are not uniformly expressed [22].

Of the 44 lncRNA candidates identified in this study, 22 are from genomic loci of PCGs (18 antisense, 1 antisense/ exonic, 2 exonic, and 1 sense/not exonic), while the remaining 22 originate from the intergenic regions. The expression of PCGs overlapping with these lncRNAs was either downregulated or remained unchanged. Specifically, the expression of ADAMTS9 (ADAM metallopeptidase with thrombospondin type 1 motif 9), HOXA11a (homeobox A11a), and PDE7B (phosphodiesterase 7B) 


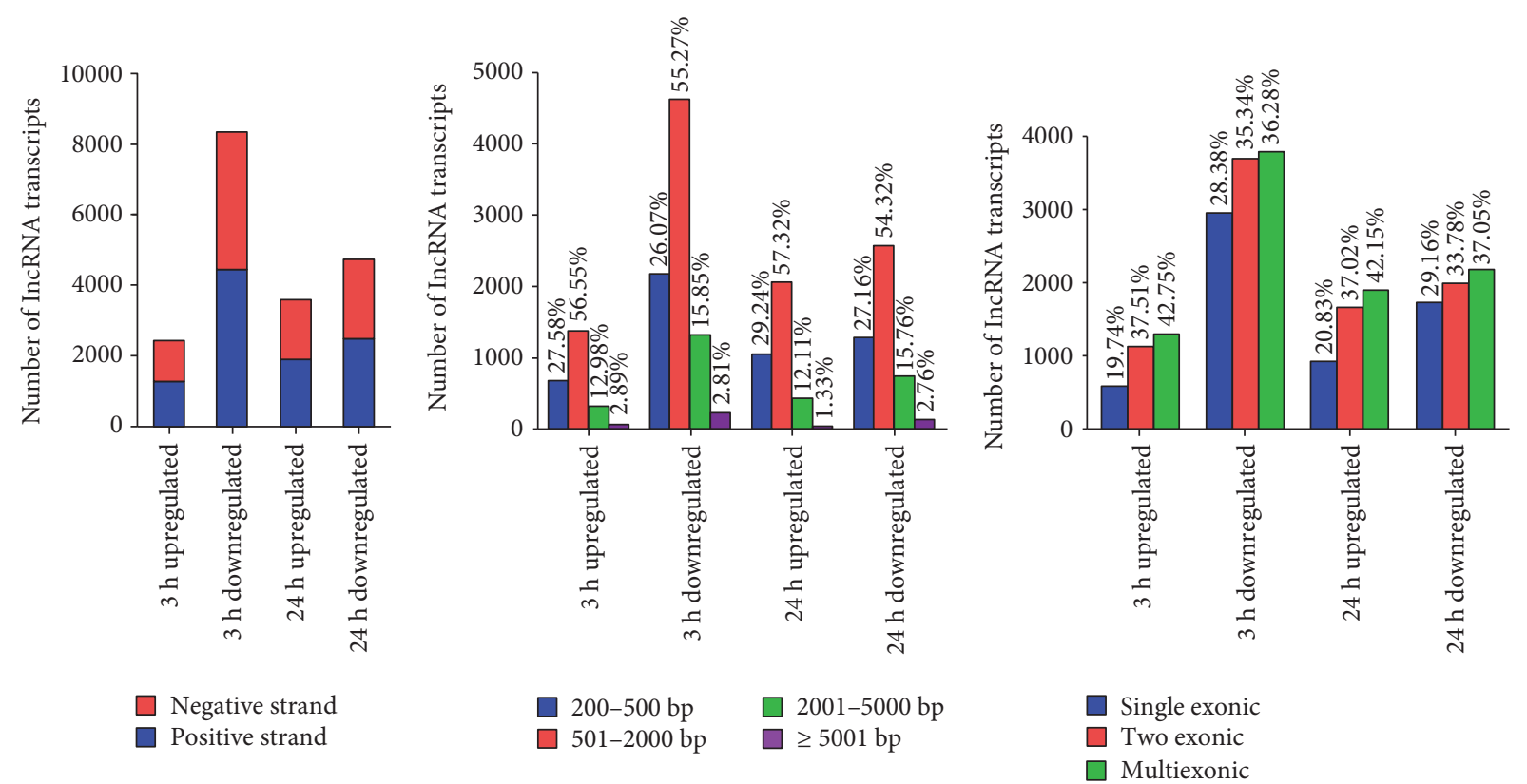

(a)

(b)

(c)

Figure 4: Cataloging of differentially expressed lncRNA transcripts from LPS-treated HMECs based on (a) strand-specific origin, (b) lengthwise distribution, and (c) number of exons.

harboring lncRNAs ADAMTS9-AS2, Hoxa11as, and NTT on the respective antisense strand was compromised, while that of ITPR1 on the opposite strand of lncRNA EGO was unaltered at both 3 or $24 \mathrm{~h}$ post-LPS treatment (Supplementary Table 3).

EGO, HOTAIRM1, and lnc-IL7R are three lncRNAs with known regulatory functions that were found to be differentially expressed in endothelial cells after LPS treatment. EGO and HOTAIRM1 have 3 and 5 splice variants, respectively. Among them, 2 splice variants of EGO and 4 splice variants of HOTAIRM1 were differentially expressed in response to LPS treatment for 3 and $24 \mathrm{~h}$. To further validate splice variant-specific expression of EGO (transcript NONHSAT087634) and HOTAIRM1 (transcript NONHSAT119666) IncRNAs, we performed qRT-PCR analysis. In agreement with the findings from our RNASeq data, the expression of both NONHSAT087634 and NONHSAT119666 transcripts was significantly upregulated at $3 \mathrm{~h}$ post-LPS treatment. At $24 \mathrm{~h}$, the expression levels of both NONHSAT087634 and NONHSAT119666 transcripts declined and were not significantly different from the basal level in mock-treated HMECs (Figures 7(a) and 7(b)). Additionally, lnc-IL7R (a known lncRNA involved in the TLR-2/4 signaling pathway) was significantly upregulated at the both 3 and $24 \mathrm{~h}$ post-LPS treatment (Figure 7).

Finally, Ingenuity Pathway Analysis revealed a number of endothelial cell signaling pathways activated in response to LPS treatment for 3 and $24 \mathrm{~h}$ (Tables 4 and 5). As expected, the pathways involved in the determination of granulocyte/ agranulocyte adhesion, death receptor signaling, IL-17 signaling, TNFR1/2 signaling, communication between innate and adaptive immune cells, signaling pathway underlying the cytokine-mediated crosstalk among different types of immune cells, role of cytokines in mediating communication between immune cells, IL-6 signaling, inflammasome pathway, role of pattern recognition receptors in recognition of bacteria and viruses, and apoptosis signaling pathways were activated in cells treated for $3 \mathrm{~h}$. On the other hand, granulocyte/agranulocyte adhesion, role of cytokines in mediating communication between immune cells, highmobility group box 1 protein (HMGB1) signaling, IL-17 signaling, role of pattern recognition receptors in recognition of bacteria and viruses, MAPK signaling, IL-6, apoptosis, chemokine signaling, and atherosclerosis signaling pathways were activated at $24 \mathrm{~h}$. Molecules involved in these important signaling pathways contributing to the downstream cellular responses are presented in Supplementary Tables 4 and 5 . Importantly, the pathways determining the role of macrophages, fibroblasts and endothelial cells in rheumatoid arthritis, atherosclerosis signaling, glucocorticoid receptor signaling, HMGB1 signaling, hepatic fibrosis/hepatic stellate cell activation, and the expression of inflammatory cytokines CXCL8, IL-6, and adhesion molecule VCAM-1 were significantly higher during LPS treatment at both 3 and $24 \mathrm{~h}$.

\section{Discussion}

The strategic location of vascular endothelium at the interface of circulating blood and underlying tissues also renders it highly susceptible to injury or infection [1]. In addition to regulating blood flow through the maintenance of an active antithrombotic surface, an important function of the endothelial cells is to provide a semipermeable barrier that facilitates the transit of the plasma and cellular constituents throughout the vasculature. LPS is a characteristic component of the outer membrane of Gram-negative bacterial cell 
TABLE 2: Differentially expressed splice variants of functionally annotated lncRNAs from HMECs following LPS treatment for 3 and $24 \mathrm{~h}$.

\begin{tabular}{|c|c|c|c|c|}
\hline $\begin{array}{l}\text { Functionally } \\
\text { annotated lncRNAs }\end{array}$ & $\begin{array}{l}\text { Total number of } \\
\text { splice variants }\end{array}$ & $\begin{array}{l}\text { Number of differentially } \\
\text { expressed splice variants }\end{array}$ & $\begin{array}{l}\text { Differentially expressed NONCODE } \\
\text { splice variants }\end{array}$ & Class \\
\hline ADAMTS9-AS2 & 11 & 2 & NONHSAT090266, NONHSAT090274 & Antisense \\
\hline \multirow[t]{3}{*}{ AK082072 } & \multirow[t]{3}{*}{39} & \multirow[t]{3}{*}{9} & $\begin{array}{c}\text { NONHSAT102610, NONHSAT102619, } \\
\text { NONHSAT102626 }\end{array}$ & \multirow[t]{3}{*}{ LINC } \\
\hline & & & $\begin{array}{c}\text { NONHSAT102631, NONHSAT102632, } \\
\text { NONHSAT102634 }\end{array}$ & \\
\hline & & & $\begin{array}{l}\text { NONHSAT102637, NONHSAT102640, } \\
\text { NONHSAT102641 }\end{array}$ & \\
\hline \multirow[t]{3}{*}{ ANRIL } & \multirow[t]{3}{*}{20} & \multirow[t]{3}{*}{8} & $\begin{array}{c}\text { NONHSAT130413, NONHSAT130414, } \\
\text { NONHSAT130416, }\end{array}$ & \multirow[t]{3}{*}{ Antisense } \\
\hline & & & $\begin{array}{l}\text { NONHSAT130417, NONHSAT130422, } \\
\text { NONHSAT130423, }\end{array}$ & \\
\hline & & & NONHSAT130425, NONHSAT130433 & \\
\hline CCAT1 & 16 & 1 & NONHSAT129019 & Antisense \\
\hline CDR1-AS & 5 & 1 & NONHSAT138820 & Antisense \\
\hline CRNDE & 13 & 2 & NONHSAT142619, NONHSAT142620 & LINC \\
\hline CTBP1-AS & 8 & 1 & NONHSAT094692 & LINC \\
\hline CYP4A22-AS1 & 2 & 2 & NONHSAT003050, NONHSAT003054 & Antisense \\
\hline Cyrano & 14 & 2 & NONHSAT041921, NONHSAT041926 & Antisense \\
\hline DHFR upstream transcripts & 1 & 1 & NONHSAT102417 & Antisense; exonic \\
\hline DHRS4-AS1 & 7 & 3 & $\begin{array}{c}\text { NONHSAT035952, NONHSAT035953, } \\
\text { NONHSAT035955 }\end{array}$ & Antisense \\
\hline DISC2 & 2 & 1 & NONHSAT010195 & Exonic \\
\hline \multirow[t]{2}{*}{ DLEU1 } & \multirow[t]{2}{*}{48} & \multirow[t]{2}{*}{6} & $\begin{array}{c}\text { NONHSAT033809, NONHSAT033813, } \\
\text { NONHSAT033815 }\end{array}$ & \multirow[t]{2}{*}{ Antisense } \\
\hline & & & $\begin{array}{c}\text { NONHSAT033822, NONHSAT033823, } \\
\text { NONHSAT033850 }\end{array}$ & \\
\hline \multirow[t]{3}{*}{ DLEU2 } & \multirow[t]{3}{*}{24} & \multirow[t]{3}{*}{8} & $\begin{array}{c}\text { NONHSAT033771, NONHSAT033774, } \\
\text { NONHSAT033780 }\end{array}$ & \multirow[t]{3}{*}{ Antisense } \\
\hline & & & $\begin{array}{c}\text { NONHSAT033788, NONHSAT033796, } \\
\text { NONHSAT033798 }\end{array}$ & \\
\hline & & & NONHSAT033800, NONHSAT033805 & \\
\hline EGO & 3 & 2 & NONHSAT087635, NONHSAT087634 & Antisense \\
\hline GAS5 & 33 & 3 & $\begin{array}{c}\text { NONHSAT007665, NONHSAT007698, } \\
\text { NONHSAT007698 }\end{array}$ & Antisense \\
\hline \multirow[t]{2}{*}{ Gomafu } & \multirow[t]{2}{*}{52} & \multirow[t]{2}{*}{6} & $\begin{array}{c}\text { NONHSAT084541, NONHSAT084545, } \\
\text { NONHSAT084547 }\end{array}$ & \multirow[t]{2}{*}{ LINC } \\
\hline & & & $\begin{array}{c}\text { NONHSAT084548, NONHSAT084549, } \\
\text { NONHSAT084551 }\end{array}$ & \\
\hline \multirow[t]{4}{*}{ H19 } & \multirow[t]{4}{*}{17} & \multirow[t]{4}{*}{10} & $\begin{array}{c}\text { NONHSAT017460, NONHSAT017461, } \\
\text { NONHSAT017461 }\end{array}$ & \multirow[t]{4}{*}{ LINC } \\
\hline & & & $\begin{array}{c}\text { NONHSAT017465, NONHSAT017466, } \\
\text { NONHSAT017467 }\end{array}$ & \\
\hline & & & $\begin{array}{c}\text { NONHSAT017469, NONHSAT017471, } \\
\text { NONHSAT017472, }\end{array}$ & \\
\hline & & & NONHSAT017474 & \\
\hline \multirow[t]{2}{*}{ HOTAIRM1 } & \multirow[t]{2}{*}{5} & \multirow[t]{2}{*}{4} & $\begin{array}{c}\text { NONHSAT119664, NONHSAT119665, } \\
\text { NONHSAT119666, }\end{array}$ & \multirow[t]{2}{*}{ LINC } \\
\hline & & & NONHSAT119667 & \\
\hline
\end{tabular}


TABLe 2: Continued.

\begin{tabular}{|c|c|c|c|c|}
\hline $\begin{array}{l}\text { Functionally } \\
\text { annotated lncRNAs }\end{array}$ & $\begin{array}{l}\text { Total number of } \\
\text { splice variants }\end{array}$ & $\begin{array}{l}\text { Number of differentially } \\
\text { expressed splice variants }\end{array}$ & $\begin{array}{c}\text { Differentially expressed NONCODE } \\
\text { splice variants } \\
\end{array}$ & Class \\
\hline Hoxa11as & 9 & 1 & NONHSAT119711 & Antisense \\
\hline \multirow[t]{8}{*}{ IPW } & \multirow[t]{8}{*}{81} & \multirow[t]{8}{*}{22} & $\begin{array}{l}\text { NONHSAT041066, NONHSAT040981, } \\
\text { NONHSAT040985 }\end{array}$ & \multirow[t]{8}{*}{ Antisense } \\
\hline & & & $\begin{array}{c}\text { NONHSAT040986, NONHSAT040988, } \\
\text { NONHSAT040989 }\end{array}$ & \\
\hline & & & $\begin{array}{c}\text { NONHSAT040990, NONHSAT040991, } \\
\text { NONHSAT041000 }\end{array}$ & \\
\hline & & & $\begin{array}{l}\text { NONHSAT041004, NONHSAT041006, } \\
\text { NONHSAT041023 }\end{array}$ & \\
\hline & & & $\begin{array}{l}\text { NONHSAT041028, NONHSAT041047, } \\
\text { NONHSAT041054 }\end{array}$ & \\
\hline & & & $\begin{array}{l}\text { NONHSAT041057, NONHSAT041060, } \\
\text { NONHSAT041061 }\end{array}$ & \\
\hline & & & $\begin{array}{l}\text { NONHSAT041062, NONHSAT041064, } \\
\text { NONHSAT041065 }\end{array}$ & \\
\hline & & & NONHSAT041140 & \\
\hline Jpx & 14 & 3 & $\begin{array}{c}\text { NONHSAT137572, NONHSAT137582, } \\
\text { NONHSAT137583 }\end{array}$ & LINC \\
\hline LINC00568 & 2 & 1 & NONHSAT006301 & LINC \\
\hline \multirow[t]{2}{*}{ LUCAT1 } & \multirow[t]{2}{*}{13} & \multirow[t]{2}{*}{4} & $\begin{array}{c}\text { NONHSAT102744, NONHSAT102748, } \\
\text { NONHSAT102749 }\end{array}$ & \multirow[t]{2}{*}{ LINC } \\
\hline & & & NONHSAT102750 & \\
\hline \multirow[t]{2}{*}{ linc00467 } & \multirow[t]{2}{*}{6} & \multirow[t]{2}{*}{6} & $\begin{array}{c}\text { NONHSAT009289, NONHSAT009290, } \\
\text { NONHSAT009291 }\end{array}$ & \multirow[t]{2}{*}{ LINC } \\
\hline & & & $\begin{array}{c}\text { NONHSAT009292, NONHSAT009293, } \\
\text { NONHSAT009294 }\end{array}$ & \\
\hline lincRNA-SFMBT2 & 8 & 1 & NONHSAT011261 & LINC \\
\hline
\end{tabular}

HMECs: human dermal microvascular endothelial cells; LINC: long intergenic noncoding RNA.

wall, a pathogen-associated molecular pattern allowing the host cells to recognize bacterial invasion, and a prototypical trigger of sepsis due to the biological response stimulating or modifying activities of lipid A [31, 32]. Also, LPS directly affects the endothelial barrier function of the blood vessels and induces potent inflammatory responses broadly characterized as a "cytokine storm" [33]. Such an enormous production of inflammatory mediators from endothelial cells after activation by LPS contributes to the pathophysiology of sepsis and endotoxic shock. It is well established that LPS activates cellular signaling mechanisms through interactions with surface TLR4, CD14, and MD2 [34] and that LPS from some bacteria, for example, Leptospira interrogans, can also signal through the TLR2 pathway [35].

It is now well appreciated that despite the transcription of a major proportion $(>80 \%)$ of human genome, PCGs account for only $\sim 2 \%$, while an overwhelming majority is transcribed into ncRNAs lacking protein-coding capacity [36]. Of these, ncRNAs longer than 200 nucleotides and endowed with the ability to interact with mRNAs, DNA, and a broad array of proteins are defined as lncRNAs $[37,38]$. Thus, in contrast to microRNAs, IncRNAs bear the potential to regulate gene expression at the levels of transcription, posttranscription, and epigenetics [7-9].
Importantly, the expression of lncRNAs occurs in a cell-, tissue-, and species-specific manner [39-41]. Although the roles of lncRNAs in the pathophysiology of cardiovascular diseases and cancer have garnered significant attention, the potential for their involvement in endothelial responses is only beginning to be elucidated. A recent study based on microarray profiling suggests differential expression of a number of lncRNAs and provides a snapshot of lncRNA/ mRNA transcriptome of macrovascular human umbilical vein endothelial cells (HUVECs) during LPS treatment [22]. In the present study, we conducted an RNA-Seq-based investigation of the expression profile of LPS-responsive lncRNAs in human microvascular endothelial cells to identify a total of 10,781 and 8310 lncRNA transcripts that were either positively or negatively regulated at 3 and $24 \mathrm{~h}$ postLPS treatment, respectively. This pool of induced or suppressed lncRNAs was then subjected to further cataloging on the basis of their strand of origin, chromosome-wise origin and distribution pattern, and exon composition. Interestingly, a majority of lncRNAs undergoing changes in their expression levels were determined to be multiexonic. Multiexonic lncRNAs composed of varying combination of exons can be differentially expressed in a cell/tissue-specific manner, and accumulating evidence suggests tissue-specific 


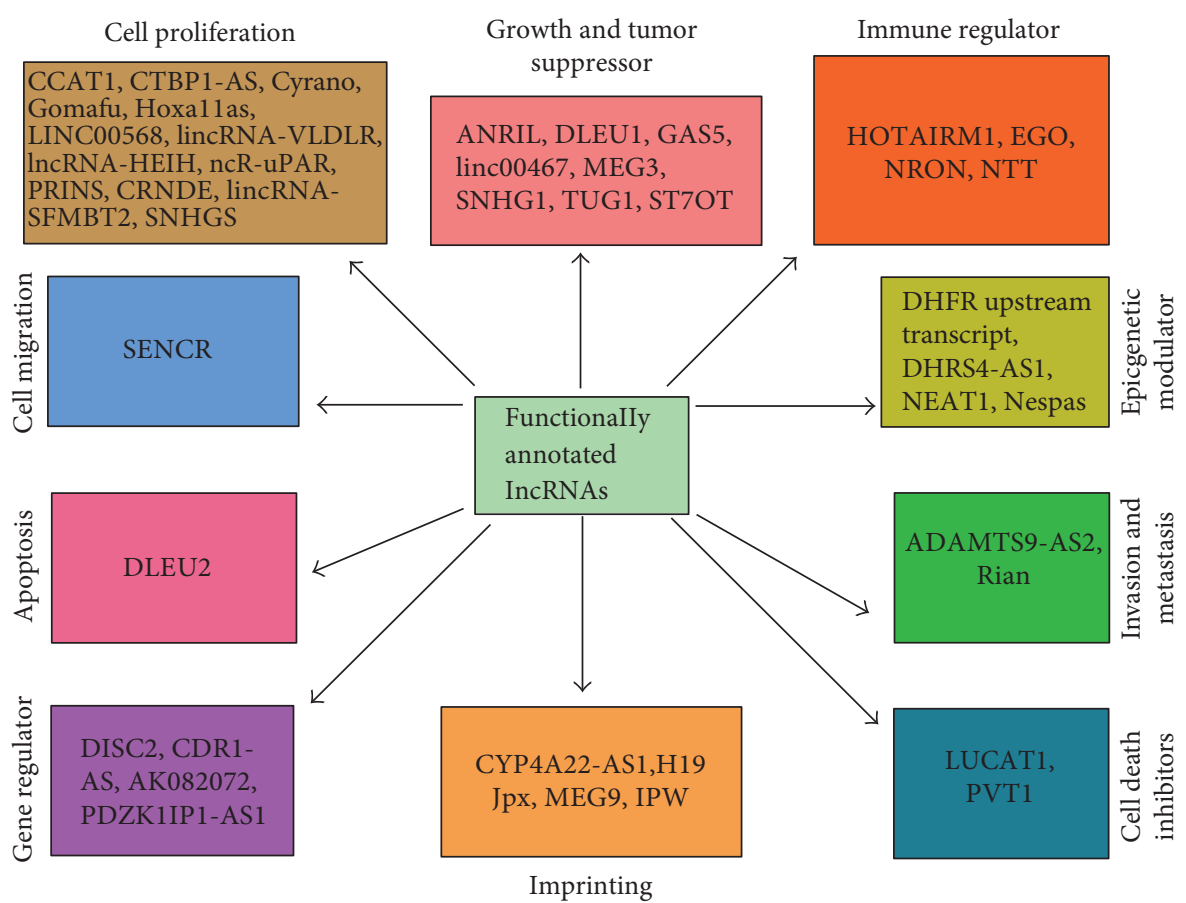

FIGURE 5: Identification of functionally annotated lncRNAs in HMECs treated with LPS for 3 and 24 h. Differentially expressed lncRNAs belong to different categories based on publicly available databases and published reports.

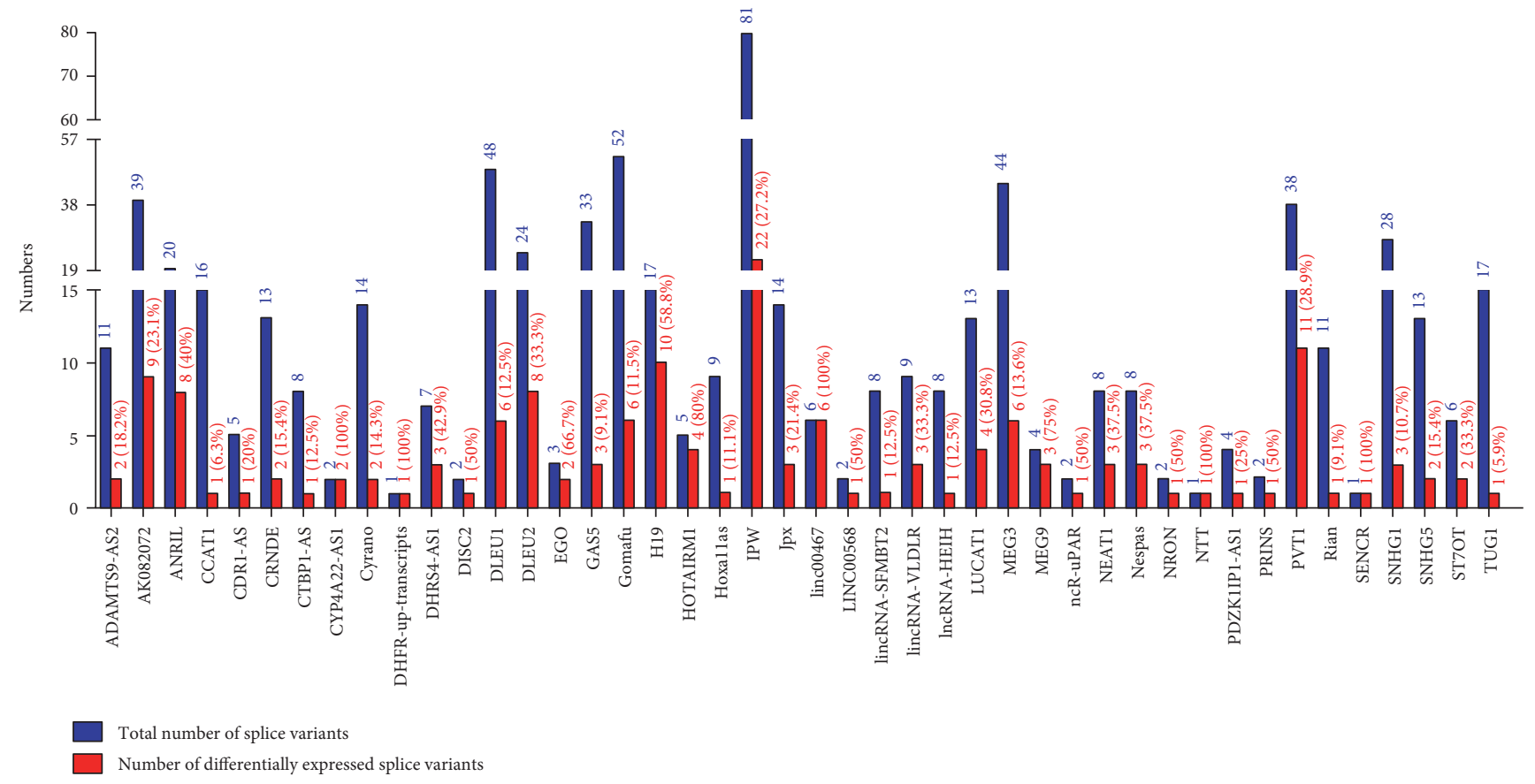

FIGURE 6: Bar diagram represents total splice variants available for 44 functionally annotated lncRNAs and their respective differentially expressed splice variants in HMECs after LPS treatment.

expression of different splice variants of individual lncRNAs [42, 43]. Accordingly, the findings of this study further demonstrate differential expression of only selective splice variants of LPS-responsive lncRNAs in microvascular endothelium.
A "search and identify" strategy based on the comparative analysis of our datasets with lncRNAdb, a database listing functionally annotated lncRNAs [28], allowed us to identify $44 \operatorname{lncRNAs}$ modulated as a consequence of LPS treatment. Among these, a subset of regulatory lncRNAs, 
TABLE 3: Comparison of lncRNAs differentially expressed during LPS treatment in HUVECs [22] and HMECs.

\begin{tabular}{|c|c|c|c|}
\hline $\begin{array}{l}\text { Differentially expressed } \\
\text { lncRNAs in HUVECs }(24 \mathrm{~h})\end{array}$ & $\begin{array}{l}\text { Differentially expressed splice variants } \\
\text { in HMECs (NONCODE IDs) }\end{array}$ & $\begin{array}{l}\text { Fold change in } \\
\text { HMECs }(3 \mathrm{~h})\end{array}$ & $\begin{array}{l}\text { Fold change in } \\
\text { HMECs }(24 \mathrm{~h})\end{array}$ \\
\hline \multirow[t]{9}{*}{ AL132709.5 } & NONHSAT039831 & 1.18 & 0.746 \\
\hline & NONHSAT039832 & 1.37 & 0.908 \\
\hline & NONHSAT039834 & 1.24 & 0.651 \\
\hline & NONHSAT039835 & 1.36 & 0.500 \\
\hline & NONHSAT039853 & 1.20 & 0.957 \\
\hline & NONHSAT039854 & 1.21 & 0.706 \\
\hline & NONHSAT039862 & 1.95 & 0.680 \\
\hline & NONHSAT039869 & 1.54 & 0.821 \\
\hline & NONHSAT140176 & 1.15 & 4.095 \\
\hline \multirow[t]{2}{*}{ CLDN10-AS1 } & NONHSAT034761 & ID $^{*}$ & $\mathrm{IU}^{*}$ \\
\hline & NONHSAT034762 & $\mathrm{IU}^{*}$ & $\mathbf{I U}^{*}$ \\
\hline \multirow[t]{7}{*}{ AC068282.3 } & NONHSAT074154 & Not detectable & Not detectable \\
\hline & NONHSAT074148 & 1.26 & 1.026 \\
\hline & NONHSAT074149 & 1.78 & 0.339 \\
\hline & NONHSAT074150 & 0.96 & 1.140 \\
\hline & NONHSAT074151 & 0.72 & 2.047 \\
\hline & NONHSAT074152 & 0.58 & 1.143 \\
\hline & NONHSAT074153 & 1.81 & 4.777 \\
\hline \multirow[t]{11}{*}{ RP11-534G20.3 } & NONHSAT012520 & 0.94 & 0.751 \\
\hline & NONHSAT012518 & $\mathrm{IU}^{*}$ & 0.350 \\
\hline & NONHSAT012519 & 3.12 & 1.370 \\
\hline & NONHSAT012522 & $\mathrm{ID}^{*}$ & 0.854 \\
\hline & NONHSAT012523 & 1.56 & 0.844 \\
\hline & NONHSAT012524 & 0.72 & 0.456 \\
\hline & NONHSAT012525 & 0.36 & ID $^{*}$ \\
\hline & NONHSAT012527 & $\mathbf{I U}^{*}$ & $\mathrm{IU}^{*}$ \\
\hline & NONHSAT012528 & 0.96 & $\mathbf{I U}^{*}$ \\
\hline & NONHSAT012534 & 0.37 & -5.861 \\
\hline & NONHSAT012521 & 2.75 & 1.090 \\
\hline \multirow[t]{4}{*}{ XLOC_009994 } & NONHSAT026026 & 1.44 & $\mathbf{I U}^{*}$ \\
\hline & NONHSAT026024 & 1.24 & 0.826 \\
\hline & NONHSAT026027 & $\mathbf{I U}^{*}$ & $\mathrm{IU}^{*}$ \\
\hline & NONHSAT140047 & Not detectable & Not detectable \\
\hline \multirow[t]{13}{*}{ AC016683.6 } & NONHSAT073764 & 1.44 & 0.341 \\
\hline & NONHSAT073753 & 3.60 & $\mathrm{ID}^{*}$ \\
\hline & NONHSAT073758 & Not detectable & Not detectable \\
\hline & NONHSAT073759 & ID* & $\mathrm{IU}^{*}$ \\
\hline & NONHSAT073761 & 0.36 & 1.345 \\
\hline & NONHSAT073762 & 2.86 & 0.743 \\
\hline & NONHSAT073763 & 1.08 & 1.168 \\
\hline & NONHSAT073767 & Not detectable & Not detectable \\
\hline & NONHSAT073766 & 1.29 & $\mathrm{IU}^{*}$ \\
\hline & NONHSAT073765 & 1.93 & 1.019 \\
\hline & NONHSAT073768 & 4.13 & 3.194 \\
\hline & NONHSAT073769 & 1.66 & 1.348 \\
\hline & NONHSAT073770 & 0.72 & 0.682 \\
\hline
\end{tabular}


TABLE 3: Continued.

\begin{tabular}{|c|c|c|c|}
\hline $\begin{array}{l}\text { Differentially expressed } \\
\text { lncRNAs in HUVECs }(24 \mathrm{~h})\end{array}$ & $\begin{array}{l}\text { Differentially expressed splice variants } \\
\text { in HMECs (NONCODE IDs) }\end{array}$ & $\begin{array}{l}\text { Fold change in } \\
\text { HMECs }(3 \mathrm{~h})\end{array}$ & $\begin{array}{l}\text { Fold change in } \\
\text { HMECs }(24 \mathrm{~h})\end{array}$ \\
\hline & NONHSAT073771 & Not detectable & Not detectable \\
\hline & NONHSAT073772 & 0.72 & 0.749 \\
\hline & NONHSAT073773 & 0.24 & $\mathrm{IU}^{*}$ \\
\hline RP11-466I1.1 & NONHSAT018559 & Not detectable & Not detectable \\
\hline RP11-184E9.2 & NONHSAT100773 & Not detectable & Not detectable \\
\hline \multirow[t]{7}{*}{ CTC-459I6.1 } & NONHSAT102422 & Not detectable & Not detectable \\
\hline & NONHSAT102423 & Not detectable & Not detectable \\
\hline & NONHSAT102425 & Not detectable & Not detectable \\
\hline & NONHSAT102426 & Not detectable & Not detectable \\
\hline & NONHSAT102427 & Not detectable & Not detectable \\
\hline & NONHSAT102428 & Not detectable & Not detectable \\
\hline & NONHSAT102424 & Not detectable & Not detectable \\
\hline \multirow[t]{2}{*}{ RP11-138B4.1 } & NONHSAT099689 & Not detectable & Not detectable \\
\hline & NONHSAT099690 & Not detectable & Not detectable \\
\hline RP11-676J12.6 & NONHSAT144771 & Not detectable & Not detectable \\
\hline XLOC_007697 & NONHSAT131377 & 0.29 & 1.136 \\
\hline \multirow[t]{8}{*}{ BX284650.1 } & NONHSAT005737 & $\mathrm{IU}^{*}$ & ID $^{*}$ \\
\hline & NONHSAT005738 & ID $^{*}$ & $I^{*}$ \\
\hline & NONHSAT005750 & 1.44 & $\mathrm{IU}^{*}$ \\
\hline & NONHSAT005751 & 0.07 & $I^{*}$ \\
\hline & NONHSAT005752 & $\mathbf{I U}^{*}$ & $\mathrm{IU}^{*}$ \\
\hline & NONHSAT005753 & Not detectable & Not detectable \\
\hline & NONHSAT005754 & Not detectable & Not detectable \\
\hline & NONHSAT005755 & Not detectable & Not detectable \\
\hline \multirow[t]{9}{*}{ RP5-907D15.2 } & NONHSAT080552 & ID $^{*}$ & $\mathrm{IU}^{*}$ \\
\hline & NONHSAT080546 & 0.68 & 0.488 \\
\hline & NONHSAT080547 & 0.36 & $\mathrm{IU}^{*}$ \\
\hline & NONHSAT080548 & Not detectable & Not detectable \\
\hline & NONHSAT080549 & Not detectable & Not detectable \\
\hline & NONHSAT080551 & Not detectable & Not detectable \\
\hline & NONHSAT080550 & 0.72 & 0.682 \\
\hline & NONHSAT080553 & Not detectable & Not detectable \\
\hline & NONHSAT080555 & Not detectable & Not detectable \\
\hline XLOC_006311 & NONHSAT124447 & 0.72 & 0.339 \\
\hline
\end{tabular}

Note: up- or downregulation by $\geq 3$-fold is indicated in bold. ID*: infinite downregulation (no detectable reads after LPS treatment/presence of detectable reads in the controls). IU*: infinite upregulation (presence of detectable reads following LPS treatment/no detectable reads in the controls).

namely, HOTAIRM1, EGO, NRON and NTT, is involved in immune regulation and the progression of disease [44-47], whereas others such as NEAT1, Nespas, DHFR upstream transcript, and DHRS4-AS1 are known as epigenetic regulators [48-51]. In addition, H19, Jpx, and MEG9 have been implicated in the regulation of genomic imprinting [52-54]. We were able to further identify other lncRNAs, namely, Gomafu, lncRNA-HEIH, Hoxallas, and PRINS, that reportedly function as inducers of cell proliferation [55-58]. In contrast, lncRNAs, such as ANRIL, GAS5, MEG3, and TUG1, have been shown to be involved in growth suppression [59-62]. It is important to also consider, however, that a recent study documents the involvement of TUG1 in promoting cell growth and chemoresistance in small cell lung cancer [63]. Together, these findings suggest the possibility of context-dependent multifunctional roles of lncRNAs. Intriguingly, a majority of regulated lncRNAs are also expressed as multiple splice variants and only selective splice variants of a particular lncRNA display differential expression in our experimental model system (Table 2 and Supplementary Table 2). It is well known that splicing constitutes a critically important step in the 


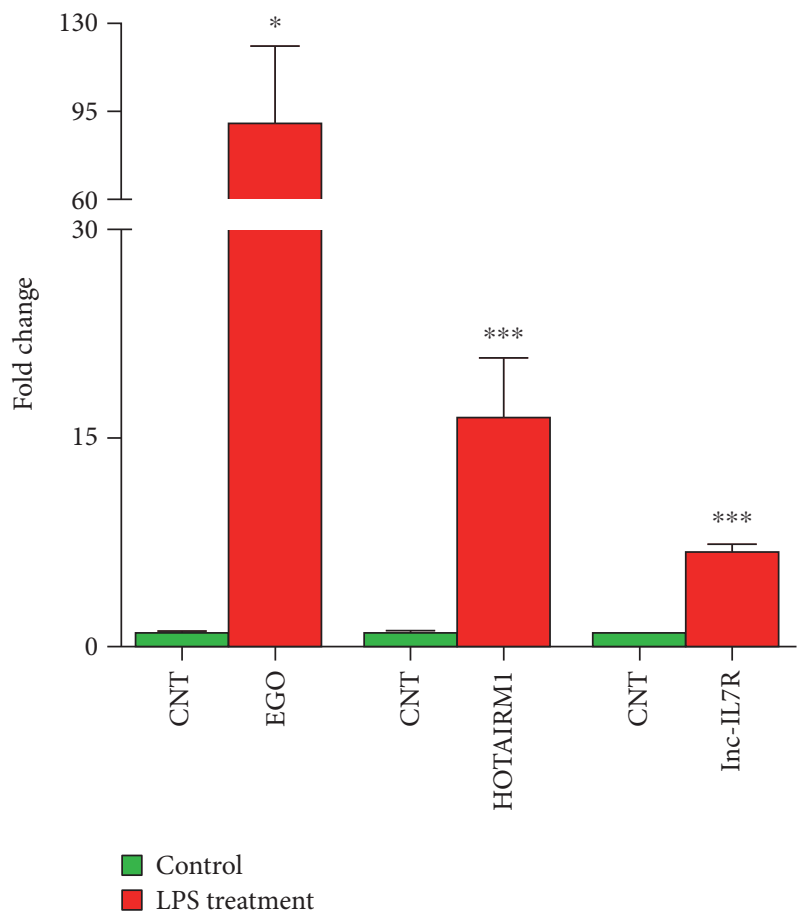

(a)

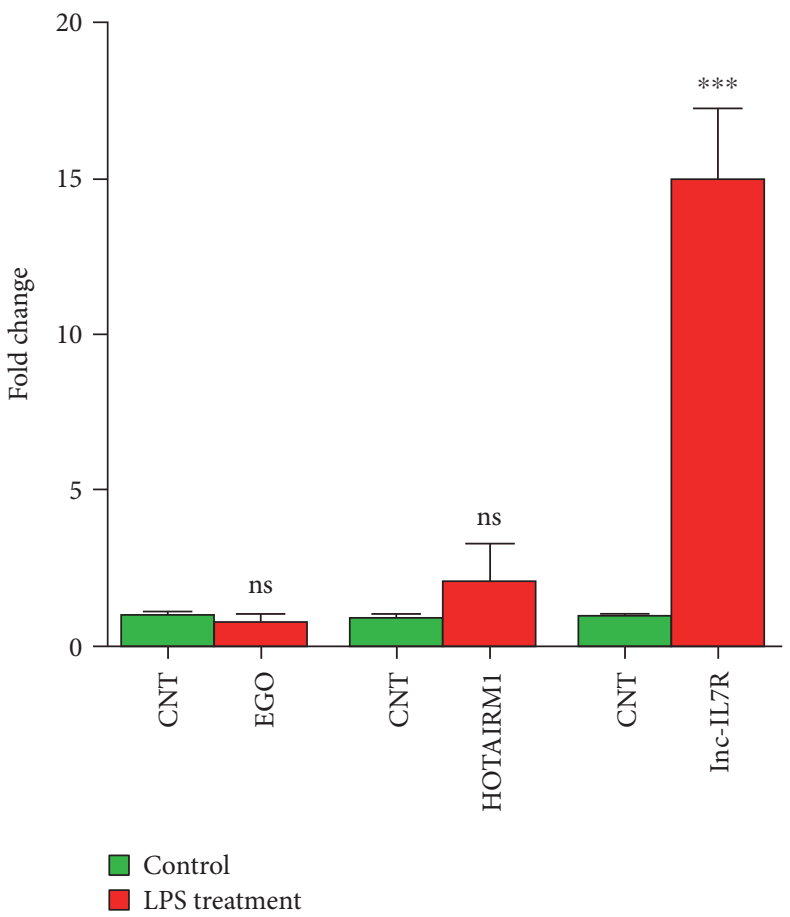

(b)

Figure 7: Quantitative RT-PCR for EGO (NONHSAT087634), HOTAIRM1 (NONHSAT119666), and lnc-IL7R expression in HMECs following LPS treatment for (a) $3 \mathrm{~h}$ and (b) $24 \mathrm{~h}\left({ }^{*} P \leq 0.05\right.$ and ${ }^{* * *} P \leq 0.001$; and ns = nonsignificant).

processing of mature RNAs within eukaryotic cells. Through this phenomenon, introns present in the premature mRNA are removed, yielding organization of exons in different/specific combinations and diversity of encoded protein sequences. Spliceosome and splicing factors are, therefore, of critical importance in determining the splice variants of transcriptome. Like premature mRNA, lncRNAs are also processed in different exonic combinations after splicing of introns [64-66] and expression of splice variants of lncRNAs for 16 tissue types has been documented in human body map $2[26,67]$. Moreover, an array of biological functions for the splice variants of lncRNAs such as MALAT1, ANRIL, Nespas, SOX2OT, and GAS5 is also being realized and reported in the literature [67-71]. Our analysis demonstrates differential expression of 6 splice variants of MEG3 amongst a total of 44 for this lncRNA (Table 2 and Supplementary Table 2). Similarly, 2 out of 3 possible splice variant transcripts of EGO and 4 of 5 splice variants of HOTAIRM1 display regulation at either 3 or $24 \mathrm{~h}$ following LPS treatment, indicating differential modulation of selective transcripts. Importantly, comparative bioinformatics analysis reveals that our data are in agreement to a large extent with the lncRNA profile of LPS-treated HUVECs, since we identified differential expression of selective transcript variants for a majority (15 of 20) of lncRNAs determined to be either highly up- or downregulated in that study [22]. A critical gap in our knowledge that needs to be addressed is that functional implications for a majority of these lncRNAs in the biology of vascular endothelium remain unknown. Also, in light of the concept of endothelial heterogeneity, the possibility of varying expression in different types of tissue- and vessel-specific endothelial beds and variations in downstream biological effects needs to be investigated in further details.

A number of previous studies have highlighted the importance of HOTAIRM1 and EGO in immune cell activation. HOTAIRM1 (HOX antisense intergenic RNA myeloid 1), a lincRNA located in the HOXA genomic cluster, modulates the expression of genes involved in myeloid differentiation. Recent evidence suggests increased expression of HOTAIRM1 in cardiomyocytes treated in vitro with LPS or those isolated from mice receiving LPS to induce sepsis [72]. EGO, another lncRNA highly expressed in the bone marrow, is involved in eosinophil differentiation of CD34 ${ }^{+}$ hematopoietic progenitor cells through regulation of expression of eosinophil granule protein, although its mode of action has not been defined yet [45]. Considering the contributions of these lncRNAs to the development and activation of innate immune responses, we further ascertained altered expression of the most highly regulated splice variant NONHSAT087634 of EGO and NONHSAT119666 of HOTAIRM1 by qRT-PCR to consolidate our findings from RNA-Seq. Also, published evidence implicates an important role for MALAT1 in enhancing the expression of TNF- $\alpha$ in cardiomyocytes after LPS treatment [73] and suggests that lincRNA-Tnfaip3 aids transcription factor $\mathrm{NF}-\kappa \mathrm{B}$ in the induced expression of inflammatory genes in mouse macrophages [74]. LPS treatment also induces the expression of lncRNA NEAT1, which has been shown to be activated in viral infections and is responsible 
TABLE 4: Significant canonical pathways identified by Ingenuity Pathway Analysis (IPA) in HMECs after $3 \mathrm{~h}$ treatment with LPS.

\begin{tabular}{|c|c|}
\hline Ingenuity canonical pathways & $-\log (P$ value $)$ \\
\hline Granulocyte adhesion and diapedesis & 4.1 \\
\hline $\begin{array}{l}\text { Role of macrophages, fibroblasts, and endothelial } \\
\text { cells in rheumatoid arthritis }\end{array}$ & 3.9 \\
\hline Agranulocyte adhesion and diapedesis & 3.7 \\
\hline Atherosclerosis signaling & 3.7 \\
\hline Glucocorticoid receptor signaling & 3.5 \\
\hline Role of IL-17A in arthritis & 3.5 \\
\hline $\begin{array}{l}\text { Activation of IRF by cytosolic pattern recognition } \\
\text { receptors }\end{array}$ & 3.5 \\
\hline $\begin{array}{l}\text { Role of hypercytokinemia/hyperchemokinemia } \\
\text { in the pathogenesis of influenza }\end{array}$ & 3.3 \\
\hline IL-17 signaling & 3.2 \\
\hline Role of IL-17A in psoriasis & 3.2 \\
\hline Death receptor signaling & 3.1 \\
\hline HMGB1 signaling & 3.0 \\
\hline Hepatic fibrosis/hepatic stellate cell activation & 3.0 \\
\hline $\begin{array}{l}\text { Differential regulation of cytokine production in } \\
\text { macrophages and T helper cells by IL-17A } \\
\text { and IL-17F }\end{array}$ & 2.9 \\
\hline TNFR2 signaling & 2.9 \\
\hline TREM1 signaling & 2.7 \\
\hline $\begin{array}{l}\text { Differential regulation of cytokine production in } \\
\text { intestinal epithelial cells by IL-17A and IL-17F }\end{array}$ & 2.7 \\
\hline $\begin{array}{l}\text { Communication between innate and adaptive } \\
\text { immune cells }\end{array}$ & 2.6 \\
\hline Acute-phase response signaling & 2.5 \\
\hline $\begin{array}{l}\text { Role of cytokines in mediating communication } \\
\text { between immune cells }\end{array}$ & 2.4 \\
\hline $\begin{array}{l}\text { Role of IL-17F in allergic inflammatory airway } \\
\text { diseases }\end{array}$ & 2.4 \\
\hline TNFR1 signaling & 2.4 \\
\hline Dendritic cell maturation & 2.2 \\
\hline IL-17A signaling in gastric cells & 2.1 \\
\hline IL-17A signaling in airway cells & 2.0 \\
\hline Inflammasome pathway & 2.0 \\
\hline $\begin{array}{l}\text { Role of pattern recognition receptors in recognition } \\
\text { of bacteria and viruses }\end{array}$ & 2.0 \\
\hline IL-6 signaling & 1.9 \\
\hline TWEAK signaling & 1.8 \\
\hline Systemic lupus erythematosus signaling & 1.8 \\
\hline CD40 signaling & 1.7 \\
\hline Hepatic cholestasis & 1.6 \\
\hline LXR/RXR activation & 1.6 \\
\hline Retinoic acid-mediated apoptosis signaling & 1.6 \\
\hline Lymphotoxin $\beta$ receptor signaling & 1.6 \\
\hline IL-17A signaling in fibroblasts & 1.6 \\
\hline PPAR signaling & 1.6 \\
\hline Eicosanoid signaling & 1.6 \\
\hline $\begin{array}{l}\text { Hematopoiesis from pluripotent } \\
\text { stem cells }\end{array}$ & 1.5 \\
\hline
\end{tabular}

TABle 4: Continued.

\begin{tabular}{lc}
\hline Ingenuity canonical pathways & $-\log (P$ value $)$ \\
\hline Altered T cell and B cell signaling in & 1.4 \\
rheumatoid arthritis & 1.3 \\
Coagulation system & 1.3 \\
B cell-activating factor signaling & 1.3 \\
Role of osteoblasts, osteoclasts, and chondrocytes & 1.3 \\
in rheumatoid arthritis & 1.3 \\
Induction of apoptosis by HIV1 & 1.3 \\
Cholecystokinin/gastrin-mediated signaling & 1.3 \\
PI3K signaling in B lymphocytes & \\
Toll-like receptor signaling &
\end{tabular}

for transcription of inflammatory cytokines through the TLR4 signaling pathway $[75,76]$. Although none of the transcript variants of MALAT-1 or lincRNA-Tnfaip3 are activated in LPS-treated HMECs under experimental conditions used in our study, we found that 1 out of 8 splice variants of NEAT-1 shows upregulation at $3 \mathrm{~h}$ posttreatment. Interestingly, NEAT1 has been associated with antiviral gene transcription and induction of cytokines such as IL-8. Our findings on the expression of lnc-IL7R, another lncRNA relatively abundant in inflammatory cells, are in agreement with a published report of its expression in HUVECs and THP1 cells in response to LPS and evidence demonstrating that targeted expression and/or activation of lnc-IL7R in LPS-treated cells diminishes the inflammatory response as reflected by decreased expression of proinflammatory cytokines IL-6 and IL-8 and cell adhesion molecules Eselectin and VCAM-1 [77]. Thus, given the stimulus and cell type specificity of lncRNAs, our findings in conjunction with the published evidence suggest potentially important roles for HOTAIRM1, EGO, NEAT1, and lncIL7R in endothelial cell responses to LPS.

Endothelial activation, injury, and dysfunction represent major contributory mechanisms underlying the pathogenesis of endotoxic shock and sepsis. Hence, the expression profiles of PCGs in vascular endothelial cells activated by LPS have been extensively investigated [20-22]. In an attempt to decipher the possibility of a correlation between the expression of lncRNAs and their adjoining PCGs, we analyzed our datasets to determine the expression of lncRNA transcripts from the loci of TLR2, TLR4, MD2, and CD14 PCGs. Intriguingly, while none of the lncRNA transcripts originating from the TLR2 and TLR4 genomic loci displayed altered expression, there were no annotated lncRNA transcripts in the genomic loci for CD14 and MD2. Exonic and antisense lncRNAs have been reported as positive and negative regulators of PCGs by diverse mechanisms such as imprinting, epigenetic regulation, splicing, nuclear/cytoplasmic trafficking, and translation [38]. Of the 44 functionally annotated lncRNAs identified in this study, 22 originate from either the sense or antisense strand for the PCGs. Keeping in mind that overlapping lncRNAs might also play a role in regulation of PCGs from the coding or opposite strand, we further examined the expression profile of these genes in our RNA-Seq dataset. 
TABLE 5: Significant canonical pathways identified by Ingenuity Pathway Analysis (IPA) in HMECs after $24 \mathrm{~h}$ treatment with LPS.

\begin{tabular}{|c|c|}
\hline Ingenuity canonical pathways & $-\log (P$ value $)$ \\
\hline $\begin{array}{l}\text { Role of IL-17F in allergic inflammatory } \\
\text { airway diseases }\end{array}$ & 7.1 \\
\hline Role of IL-17A in arthritis & 5.7 \\
\hline Agranulocyte adhesion and diapedesis & 5.7 \\
\hline Granulocyte adhesion and diapedesis & 5.4 \\
\hline Role of IL-17A in psoriasis & 4.9 \\
\hline $\begin{array}{l}\text { Role of hypercytokinemia/hyperchemokinemia } \\
\text { in the pathogenesis of influenza }\end{array}$ & 4.6 \\
\hline $\begin{array}{l}\text { Role of macrophages, fibroblasts, and endothelial } \\
\text { cells in rheumatoid arthritis }\end{array}$ & 4.6 \\
\hline $\begin{array}{l}\text { Communication between innate and adaptive } \\
\text { immune cells }\end{array}$ & 4.5 \\
\hline $\begin{array}{l}\text { Differential regulation of cytokine production in } \\
\text { macrophages and T helper cells by IL-17A } \\
\text { and IL-17F }\end{array}$ & 4.3 \\
\hline HMGB1 signaling & 4.2 \\
\hline $\begin{array}{l}\text { Differential regulation of cytokine production } \\
\text { in intestinal epithelial cells by IL-17A and IL-17F }\end{array}$ & 4.0 \\
\hline $\begin{array}{l}\text { Role of cytokines in mediating communication } \\
\text { between immune cells }\end{array}$ & 3.5 \\
\hline Glucocorticoid receptor signaling & 3.5 \\
\hline Atherosclerosis signaling & 3.4 \\
\hline Retinol biosynthesis & 3.4 \\
\hline $\begin{array}{l}\text { Hepatic fibrosis/hepatic stellate cell } \\
\text { activation }\end{array}$ & 3.0 \\
\hline Acute-phase response signaling & 2.9 \\
\hline IL-17 signaling & 2.8 \\
\hline Graft-versus-host disease signaling & 2.8 \\
\hline IL-17A signaling in fibroblasts & 2.6 \\
\hline $\begin{array}{l}\text { Hematopoiesis from pluripotent } \\
\text { stem cells }\end{array}$ & 2.5 \\
\hline Dendritic cell maturation & 2.5 \\
\hline TREM1 signaling & 2.4 \\
\hline IL-17A signaling in gastric cells & 2.3 \\
\hline IL-17A signaling in airway cells & 2.3 \\
\hline The visual cycle & 2.3 \\
\hline $\begin{array}{l}\text { Role of pattern recognition receptors in recognition } \\
\text { of bacteria and viruses }\end{array}$ & 2.2 \\
\hline $\begin{array}{l}\text { Altered } \mathrm{T} \text { cell and B cell signaling in rheumatoid } \\
\text { arthritis }\end{array}$ & 2.2 \\
\hline $\begin{array}{l}\text { Role of osteoblasts, osteoclasts, and chondrocytes } \\
\text { in rheumatoid arthritis }\end{array}$ & 2.0 \\
\hline Systemic lupus erythematosus signaling & 2.0 \\
\hline $\begin{array}{l}\text { Activation of IRF by cytosolic pattern recognition } \\
\text { receptors }\end{array}$ & 1.9 \\
\hline $\begin{array}{l}\text { Role of MAPK signaling in the pathogenesis of } \\
\text { influenza }\end{array}$ & 1.9 \\
\hline Hepatic cholestasis & 1.9 \\
\hline LXR/RXR activation & 1.9 \\
\hline Retinoate biosynthesis I & 1.8 \\
\hline Bile acid biosynthesis, neutral pathway & 1.8 \\
\hline
\end{tabular}

TABle 5: Continued.

\begin{tabular}{lc}
\hline Ingenuity canonical pathways & $-\log (P$ value $)$ \\
\hline Methylglyoxal degradation III & 1.8 \\
Airway pathology in chronic obstructive pulmo- & 1.8 \\
nary disease & 1.6 \\
IL-6 signaling & 1.5 \\
Crosstalk between dendritic cells and natural killer & \\
cells & 1.5 \\
Triacylglycerol degradation & 1.5 \\
Induction of apoptosis by HIV1 & 1.5 \\
Cholecystokinin/gastrin-mediated signaling & 1.5 \\
OX40 signaling pathway & 1.4 \\
Chemokine signaling & 1.4 \\
Role of tissue factor in cancer & 1.3 \\
Antigen presentation pathway & 1.3 \\
PPAR signaling & \\
\hline
\end{tabular}

A positive correlation between ADAMTS9-AS2 lncRNA and its antisense PCG ADAMTS9, responsible for cell migration, has recently been demonstrated [78]. Accordingly, we noticed that the expression of both transcripts of ADAMTS9-AS2 lncRNA changes with the corresponding mRNA at 3 and $24 \mathrm{~h}$. We further observed a similar expression pattern for the genes HOXA11a and PDE7B antisense to Hoxallas and NTT lncRNAs, respectively. Wagner et al. have recently dissected the functional importance of EGO in eosinophils [45]. Although genomic loci of EGO are nested within the intronic region of the ITPR1 gene on the opposite strand, the expression of this lncRNA does not correlate with the expression of mRNA. Interestingly, the level of ITPR1 mRNA does not change after LPS treatment in our dataset, supporting a previous finding [45]. Ingenuity Pathway Analysis revealed that after LPS treatment, a number of differentially regulated pathways related to immune response, apoptosis, proliferation, and cell adhesion were activated at 3 and $24 \mathrm{~h}$, and our findings (Figure 5) indicate that a number of functionally annotated lncRNAs might be associated with these pathways.

The limitation of this study is that a majority of the lncRNA splice variants have not been characterized in detail as of yet, thus limiting our efforts to functionally annotate their role in vital cellular functions such as immune regulation, epigenetic modulation, cell proliferation, and growth suppression. Therefore, further investigations aimed at defining modulatory effects of specific splice variants during the pathogenesis of sepsis and septic shock syndrome should reveal important new insights into the vascular endothelium's responses to LPS in particular and pathophysiology of sepsis syndrome in general.

\section{Conflicts of Interest}

The authors declare no conflict of interests or competing financial interests regarding the publication of this paper. 


\section{Authors' Contributions}

Imran $\mathrm{H}$. Chowdhury designed and performed in vitro experiments; conducted RNA-Seq, q-RT-PCR, and bioinformatics analyses; analyzed the resultant data; and prepared the manuscript draft. Hema P. Narra assisted with the RNA-Seq analysis and preparation of the manuscript. Kamil Khanipov and Yuriy Fofanov contributed to bioinformatics analyses and interpretation of results. Abha Sahni and Jignesh Patel prepared and provided cultures of HMECs. Casey L. C. Schroeder assisted with the data analysis and preparation of figures. Sanjeev K. Sahni conceived, organized, and supervised the conduct of experiments and edited and finalized the manuscript. All authors read and approved the final draft of the manuscript.

\section{Acknowledgments}

This work was supported by James W. McLaughlin postdoctoral fellowship at the University of Texas Medical Branch (UTMB), Galveston, TX, USA, to Imran H. Chowdhury, and institutional support funds from the UTMB. The authors sincerely thank Dr. Saravanan Thangamani, UTMB Department of Pathology, for prompt and kind assistance with the performance of Ingenuity Pathway Analysis.

\section{References}

[1] S. M. Dauphinee and A. Karsan, "Lipopolysaccharide signaling in endothelial cells," Laboratory Investigation; a Journal of Technical Methods and Pathology, vol. 86, no. 1, pp. 9-22, 2006.

[2] A. G. Randolph and R. J. McCulloh, "Pediatric sepsis: important considerations for diagnosing and managing severe infections in infants, children, and adolescents," Virulence, vol. 5, no. 1, pp. 179-189, 2014

[3] J. L. Vincent, D. R. Nelson, and M. D. Williams, "Is worsening multiple organ failure the cause of death in patients with severe sepsis?," Critical Care Medicine, vol. 39, no. 5, pp. 1050-1055, 2011.

[4] C. Chelazzi, G. Villa, P. Mancinelli, A. R. De Gaudio, and C. Adembri, "Glycocalyx and sepsis-induced alterations in vascular permeability," Critical Care, vol. 19, no. 1, 26 pages, 2015.

[5] S. Danese, E. Dejana, and C. Fiocchi, "Immune regulation by microvascular endothelial cells: directing innate and adaptive immunity, coagulation, and inflammation," Journal of Immunology, vol. 178, no. 10, pp. 6017-6022, 2007.

[6] J. A. Heward and M. A. Lindsay, "Long non-coding RNAs in the regulation of the immune response," Trends in Immunology, vol. 35, no. 9, pp. 408-419, 2014.

[7] J. Cao, "The functional role of long non-coding RNAs and epigenetics," Biological Procedures Online, vol. 16, no. 1, 11 pages, 2014.

[8] P. O. Angrand, C. Vennin, X. Le Bourhis, and E. Adriaenssens, "The role of long non-coding RNAs in genome formatting and expression," Frontiers in Genetics, vol. 6, p. 165, 2015.

[9] A. R. Karapetyan, C. Buiting, R. A. Kuiper, and M. W. Coolen, "Regulatory roles for long ncRNA and mRNA," Cancer, vol. 5, no. 2, pp. 462-490, 2013.
[10] K. K. Singh, P. N. Matkar, A. Quan et al., "Investigation of TGF $\beta 1$-induced long noncoding RNAs in endothelial cells," International Journal of Vascular Medicine, vol. 2016, Article ID 2459687, 12 pages, 2016.

[11] L. E. Mantella, K. K. Singh, P. Sandhu et al., "Fingerprint of long non-coding RNA regulated by cyclic mechanical stretch in human aortic smooth muscle cells: implications for hypertension," Molecular and Cellular Biochemistry, 2017.

[12] Q. Zhang, C. Y. Chen, V. S. Yedavalli, and K. T. Jeang, "NEAT1 long noncoding RNA and paraspeckle bodies modulate HIV-1 posttranscriptional expression," mBio, vol. 4, no. 1, pp. e00596-e00512, 2013.

[13] L. Tan, J. T. Yu, N. Hu, and L. Tan, "Non-coding RNAs in Alzheimer's disease," Molecular Neurobiology, vol. 47, no. 1, pp. 382-393, 2013.

[14] S. Uchida and S. Dimmeler, "Long noncoding RNAs in cardiovascular diseases," Circulation Research, vol. 116, no. 4, pp. 737-750, 2015.

[15] M. Huarte, "The emerging role of lncRNAs in cancer," Nature Medicine, vol. 21, no. 11, pp. 1253-1261, 2015.

[16] K. K. Singh, P. N. Matkar, Y. Pan et al., "Endothelial long non-coding RNAs regulated by oxidized LDL," Molecular and Cellular Biochemistry, vol. 431, no. 1-2, pp. 139-149, 2017.

[17] Q. Liu and J. L. Ding, “The molecular mechanisms of TLRsignaling cooperation in cytokine regulation," Immunology and Cell Biology, vol. 94, no. 6, pp. 538-542, 2016.

[18] M. Yamamoto, S. Yamazaki, S. Uematsu et al., "Regulation of Toll/IL-1-receptor-mediated gene expression by the inducible nuclear protein $\mathrm{I} \kappa \mathrm{B} \zeta$," Nature, vol. 430, no. 6996, pp. 218 222, 2004.

[19] N. Munshi, A. Z. Fernandis, R. P. Cherla, I. W. Park, and R. K. Ganju, "Lipopolysaccharide-induced apoptosis of endothelial cells and its inhibition by vascular endothelial growth factor," Journal of Immunology, vol. 168, no. 11, pp. 5860-5866, 2002.

[20] G. C. Beck, N. Rafat, P. Brinkkoetter et al., "Heterogeneity in lipopolysaccharide responsiveness of endothelial cells identified by gene expression profiling: role of transcription factors," Clinical and Experimental Immunology, vol. 143, no. 3, pp. 523-533, 2006.

[21] S. Yu, X. Chen, M. Xiu et al., "The regulation of Jmjd3 upon the expression of NF- $\kappa \mathrm{B}$ downstream inflammatory genes in LPS activated vascular endothelial cells," Biochemical and Biophysical Research Communications, vol. 485, no. 1, pp. 62-68, 2017.

[22] K. K. Singh, P. N. Matkar, S. Muhammad et al., "Investigation of novel LPS-induced differentially expressed long non-coding RNAs in endothelial cells," Molecular and Cellular Biochemistry, vol. 421, no. 1-2, pp. 157-168, 2016.

[23] E. Rydkina, L. C. Turpin, and S. K. Sahni, "Rickettsia rickettsii infection of human macrovascular and microvascular endothelial cells reveals activation of both common and cell typespecific host response mechanisms," Infection and Immunity, vol. 78, no. 6, pp. 2599-2606, 2010.

[24] C. L. Schroeder, H. P. Narra, M. Rojas et al., "Bacterial small RNAs in the genus Rickettsia," BMC Genomics, vol. 16, no. 1, 1075 pages, 2015.

[25] H. P. Narra, C. L. Schroeder, A. Sahni et al., "Small regulatory RNAs of Rickettsia conorii," Scientific Reports, vol. 6, no. 1, article 36728, 2016. 
[26] C. Xie, J. Yuan, H. Li et al., "NONCODEv4: exploring the world of long non-coding RNA genes," Nucleic Acids Research, vol. 42, D1, pp. D98-103, 2014.

[27] A. Mortazavi, B. A. Williams, K. McCue, L. Schaeffer, and B. Wold, "Mapping and quantifying mammalian transcriptomes by RNA-Seq," Nature Methods, vol. 5, no. 7, pp. 621628, 2008.

[28] X. C. Quek, D. W. Thomson, J. L. Maag et al., "IncRNAdb v2.0: expanding the reference database for functional long noncoding RNAs," Nucleic Acids Research, vol. 43, no. D1, pp. D168-D173, 2015.

[29] J. Y. Choy, P. L. Boon, N. Bertin, and M. J. Fullwood, “A resource of ribosomal RNA-depleted RNA-Seq data from different normal adult and fetal human tissues," Scientific Data, vol. 2, article 150063, 2015.

[30] R. Huang, M. Jaritz, P. Guenzl et al., "An RNA-Seq strategy to detect the complete coding and non-coding transcriptome including full-length imprinted macro ncRNAs," PLoS One, vol. 6, no. 11, article e27288, 2011.

[31] A. Steimle, I. B. Autenrieth, and J. S. Frick, "Structure and function: lipid A modifications in commensals and pathogens," International Journal of Medical Microbiology: IJMM, vol. 306, no. 5, pp. 290-301, 2016.

[32] E. S. Van Amersfoort, T. J. Van Berkel, and J. Kuiper, "Receptors, mediators, and mechanisms involved in bacterial sepsis and septic shock," Clinical Microbiology Reviews, vol. 16, no. 3, pp. 379-414, 2003.

[33] A. H. Sprague and R. A. Khalil, "Inflammatory cytokines in vascular dysfunction and vascular disease," Biochemical Pharmacology, vol. 78, no. 6, pp. 539-552, 2009.

[34] E. Levy, G. Xanthou, E. Petrakou et al., "Distinct roles of TLR4 and CD14 in LPS-induced inflammatory responses of neonates," Pediatric Research, vol. 66, no. 2, pp. 179184, 2009.

[35] L. Oliveira-Nascimento, P. Massari, and L. M. Wetzler, "The role of TLR2 in infection and immunity," Frontiers in Immunology, vol. 3, p. 79, 2012.

[36] J. Hackermuller, K. Reiche, C. Otto et al., "Cell cycle, oncogenic and tumor suppressor pathways regulate numerous long and macro non-protein-coding RNAs," Genome Biology, vol. 15, no. 3, article R48, 2014.

[37] J. R. Prensner and A. M. Chinnaiyan, "The emergence of lncRNAs in cancer biology," Cancer Discovery, vol. 1, no. 5, pp. 391-407, 2011.

[38] V. E. Villegas and P. G. Zaphiropoulos, "Neighboring gene regulation by antisense long non-coding RNAs," International Journal of Molecular Sciences, vol. 16, no. 2, pp. 3251-3266, 2015.

[39] C. Kutter, S. Watt, K. Stefflova et al., "Rapid turnover of long noncoding RNAs and the evolution of gene expression," PLoS Genetics, vol. 8, no. 7, article e1002841, 2012.

[40] H. Mirsafian, S. S. Manda, C. J. Mitchell et al., "Long noncoding RNA expression in primary human monocytes," Genomics, vol. 108, no. 1, pp. 37-45, 2016.

[41] Z. Jehan, S. Vallinayagam, S. Tiwari et al., "Novel noncoding RNA from human Y distal heterochromatic block (Yq12) generates testis-specific chimeric CDC2L2," Genome Research, vol. 17, no. 4, pp. 433-440, 2007.

[42] Y. Zhang, K. Chen, S. A. Sloan et al., “An RNA-sequencing transcriptome and splicing database of glia, neurons, and vascular cells of the cerebral cortex," The Journal of Neuroscience:
The Official Journal of the Society for Neuroscience, vol. 34, no. 36, pp. 11929-11947, 2014.

[43] B. C. Ellis, P. L. Molloy, and L. D. Graham, "CRNDE: a long non-coding RNA involved in CanceR, Neurobiology, and DEvelopment," Frontiers in Genetics, vol. 3, 270 pages, 2012.

[44] X. Zhang, Z. Lian, C. Padden et al., “A myelopoiesis-associated regulatory intergenic noncoding RNA transcript within the human HOXA cluster," Blood, vol. 113, no. 11, pp. 2526-2534, 2009.

[45] L. A. Wagner, C. J. Christensen, D. M. Dunn et al., "EGO, a novel, noncoding RNA gene, regulates eosinophil granule protein transcript expression," Blood, vol. 109, no. 12, pp. 5191-5198, 2007.

[46] A. T. Willingham, A. P. Orth, S. Batalov et al., "A strategy for probing the function of noncoding RNAs finds a repressor of NFAT," Science, vol. 309, no. 5740, pp. 1570-1573, 2005.

[47] A. Y. Liu, B. S. Torchia, B. R. Migeon, and R. F. Siliciano, "The human NTT gene: identification of a novel $17-\mathrm{kb}$ noncoding nuclear RNA expressed in activated $\mathrm{CD} 4^{+} \mathrm{T}$ cells," Genomics, vol. 39, no. 2, pp. 171-184, 1997.

[48] M. Guttman, J. Donaghey, B. W. Carey et al., "lincRNAs act in the circuitry controlling pluripotency and differentiation," Nature, vol. 477, no. 7364, pp. 295-300, 2011.

[49] S. Chillambhi, S. Turan, D. Y. Hwang, H. C. Chen, H. Jüppner, and M. Bastepe, "Deletion of the noncoding GNAS antisense transcript causes pseudohypoparathyroidism type $\mathrm{Ib}$ and biparental defects of GNAS methylation in cis," The Journal of Clinical Endocrinology and Metabolism, vol. 95, no. 8, pp. 3993-4002, 2010.

[50] I. Martianov, A. Ramadass, A. Serra Barros, N. Chow, and A. Akoulitchev, "Repression of the human dihydrofolate reductase gene by a non-coding interfering transcript," Nature, vol. 445, no. 7128, pp. 666-670, 2007.

[51] Q. Li, Z. Su, X. Xu et al., "AS1DHRS4, a head-to-head natural antisense transcript, silences the DHRS4 gene cluster in cis and trans," Proceedings of the National Academy of Sciences of the United States of America, vol. 109, no. 35, pp. 14110-14115, 2012.

[52] A. Gabory, H. Jammes, and L. Dandolo, "The H19 locus: role of an imprinted non-coding RNA in growth and development," BioEssays: News and Reviews in Molecular, Cellular and Developmental Biology, vol. 32, no. 6, pp. 473-480, 2010.

[53] C. Chureau, M. Prissette, A. Bourdet et al., "Comparative sequence analysis of the $\mathrm{X}$-inactivation center region in mouse, human, and bovine," Genome Research, vol. 12, no. 6, pp. 894908, 2002.

[54] J. P. Hagan, B. L. O'Neill, C. L. Stewart, S. V. Kozlov, and C. M. Croce, "At least ten genes define the imprinted Dlk1Dio3 cluster on mouse chromosome 12qF1," PLoS One, vol. 4, no. 2, article e4352, 2009.

[55] T. R. Mercer, I. A. Qureshi, S. Gokhan et al., "Long noncoding RNAs in neuronal-glial fate specification and oligodendrocyte lineage maturation," BMC Neuroscience, vol. 11, no. 1, 14 pages, 2010.

[56] F. Yang, L. Zhang, X. S. Huo et al., "Long noncoding RNA high expression in hepatocellular carcinoma facilitates tumor growth through enhancer of zeste homolog 2 in humans," Hepatology, vol. 54, no. 5, pp. 1679-1689, 2011. 
[57] H. M. Hsieh-Li, D. P. Witte, M. Weinstein et al., "Hoxa 11 structure, extensive antisense transcription, and function in male and female fertility," Development, vol. 121, no. 5, pp. 1373-1385, 1995.

[58] E. Sonkoly, Z. Bata-Csorgo, A. Pivarcsi et al., "Identification and characterization of a novel, psoriasis susceptibilityrelated noncoding RNA gene, PRINS," The Journal of Biological Chemistry, vol. 280, no. 25, pp. 24159-24167, 2005.

[59] W. Deng, J. Wang, J. Zhang, J. Cai, Z. Bai, and Z. Zhang, "TET2 regulates LncRNA-ANRIL expression and inhibits the growth of human gastric cancer cells," IUBMB Life, vol. 68, no. 5, pp. 355-364, 2016.

[60] M. Mourtada-Maarabouni, A. M. Hasan, F. Farzaneh, and G. T. Williams, "Inhibition of human T-cell proliferation by mammalian target of rapamycin (mTOR) antagonists requires noncoding RNA growth-arrest-specific transcript 5 (GAS5)," Molecular Pharmacology, vol. 78, no. 1, pp. 1928, 2010.

[61] X. Zhang, Y. Zhou, K. R. Mehta et al., "A pituitary-derived MEG3 isoform functions as a growth suppressor in tumor cells," The Journal of Clinical Endocrinology and Metabolism, vol. 88, no. 11, pp. 5119-5126, 2003.

[62] A. M. Khalil, M. Guttman, M. Huarte et al., "Many human large intergenic noncoding RNAs associate with chromatinmodifying complexes and affect gene expression," Proceedings of the National Academy of Sciences of the United States of America, vol. 106, no. 28, pp. 11667-11672, 2009.

[63] Y. Niu, F. Ma, W. Huang et al., "Long non-coding RNA TUG1 is involved in cell growth and chemoresistance of small cell lung cancer by regulating LIMK2b via EZH2," Molecular Cancer, vol. 16, no. 1, p. 5, 2017.

[64] L. Yang, "Splicing noncoding RNAs from the inside out," Wiley Interdisciplinary Reviews. RNA, vol. 6, no. 6, pp. 651660, 2015.

[65] H. Tsuiji, R. Yoshimoto, Y. Hasegawa, M. Furuno, M. Yoshida, and S. Nakagawa, "Competition between a noncoding exon and introns: Gomafu contains tandem UACUAAC repeats and associates with splicing factor-1," Genes to Cells: Devoted to Molecular \& Cellular Mechanisms, vol. 16, no. 5, pp. 479490, 2011.

[66] B. S. Clark and S. Blackshaw, "Long non-coding RNAdependent transcriptional regulation in neuronal development and disease," Frontiers in Genetics, vol. 5, p. 164, 2014.

[67] E. A. Gibb, E. A. Vucic, K. S. Enfield et al., "Human cancer long non-coding RNA transcriptomes," PLoS One, vol. 6, no. 10, article e25915, 2011.

[68] K. Sato, H. Nakagawa, A. Tajima, K. Yoshida, and I. Inoue, "ANRIL is implicated in the regulation of nucleus and potential transcriptional target of E2F1," Oncology Reports, vol. 24, no. 3, pp. 701-707, 2010.

[69] C. M. Williamson, J. A. Skinner, G. Kelsey, and J. Peters, "Alternative non-coding splice variants of Nespas, an imprinted gene antisense to Nesp in the Gnas imprinting cluster," Mammalian Genome: Official Journal of the International Mammalian Genome Society, vol. 13, no. 2, pp. 74-79, 2002.

[70] A. Shahryari, M. R. Rafiee, Y. Fouani et al., "Two novel splice variants of SOX2OT, SOX2OT-S1, and SOX2OT-S2 are coupregulated with SOX2 and OCT4 in esophageal squamous cell carcinoma," Stem Cells, vol. 32, no. 1, pp. 126-134, 2014.
[71] A. Renganathan, J. Kresoja-Rakic, N. Echeverry et al., "GAS5 long non-coding RNA in malignant pleural mesothelioma," Molecular Cancer, vol. 13, no. 1, 119 pages, 2014.

[72] H. Wu, J. Liu, W. Li, and Z. Li, "LncRNA-HOTAIR promotes TNF- $\alpha$ production in cardiomyocytes of LPS-induced sepsis mice by activating NF- $\kappa$ B pathway," Biochemical and Biophysical Research Communications, vol. 471, no. 1, pp. 240-246, 2016.

[73] Y. T. Zhuang, D. Y. Xu, G. Y. Wang, J. L. Sun, Y. Huang, and S. Z. Wang, "IL-6 induced lncRNA MALAT1 enhances TNF- $\alpha$ expression in LPS-induced septic cardiomyocytes via activation of SAA3," European Review for Medical and Pharmacological Sciences, vol. 21, no. 2, pp. 302-309, 2017.

[74] T. Y. Lai, S. D. Wu, M. H. Tsai et al., "Transcription of Tnfaip3 is regulated by NF- $\kappa \mathrm{B}$ and $\mathrm{p} 38$ via $\mathrm{C} / \mathrm{EBP} \beta$ in activated macrophages," PLoS One, vol. 8, no. 9, article e73153, 2013.

[75] F. Zhang, L. Wu, J. Qian et al., "Identification of the long noncoding RNA NEAT1 as a novel inflammatory regulator acting through MAPK pathway in human lupus," Journal of Autoimmunity, vol. 75, pp. 96-104, 2016.

[76] K. Imamura, N. Imamachi, G. Akizuki et al., "Long noncoding RNA NEAT1-dependent SFPQ relocation from promoter region to paraspeckle mediates IL8 expression upon immune stimuli," Molecular Cell, vol. 53, no. 3, pp. 393-406, 2014.

[77] H. Cui, N. Xie, Z. Tan et al., "The human long noncoding RNA lnc-IL7R regulates the inflammatory response," European Journal of Immunology, vol. 44, no. 7, pp. 2085-2095, 2014.

[78] J. Yao, B. Zhou, J. Zhang et al., "A new tumor suppressor LncRNA ADAMTS9-AS2 is regulated by DNMT1 and inhibits migration of glioma cells," Tumour Biology: the Journal of the International Society for Oncodevelopmental Biology and Medicine, vol. 35, no. 8, pp. 7935-7944, 2014. 


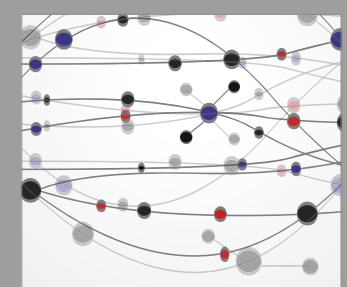

The Scientific World Journal
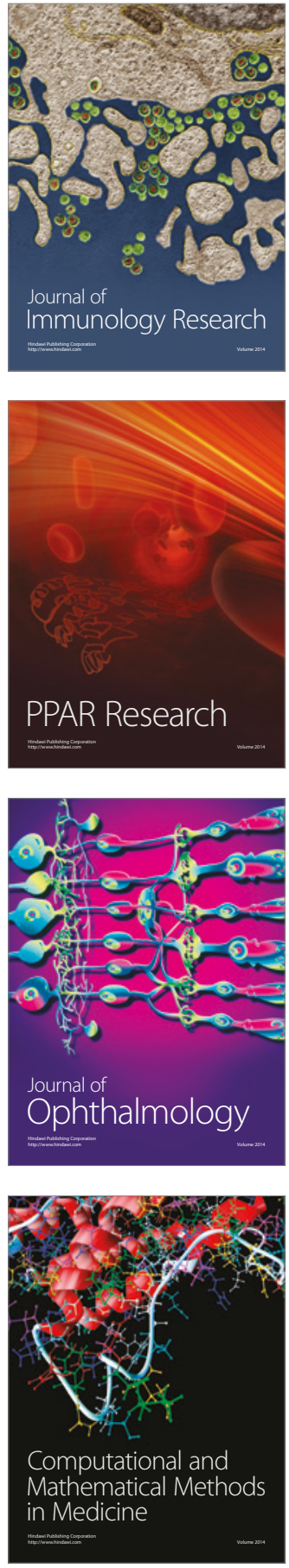

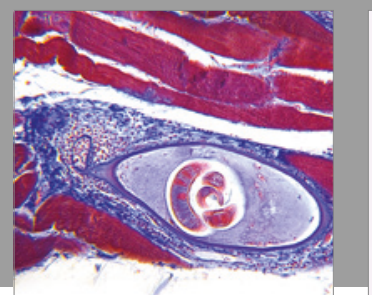

Gastroenterology Research and Practice
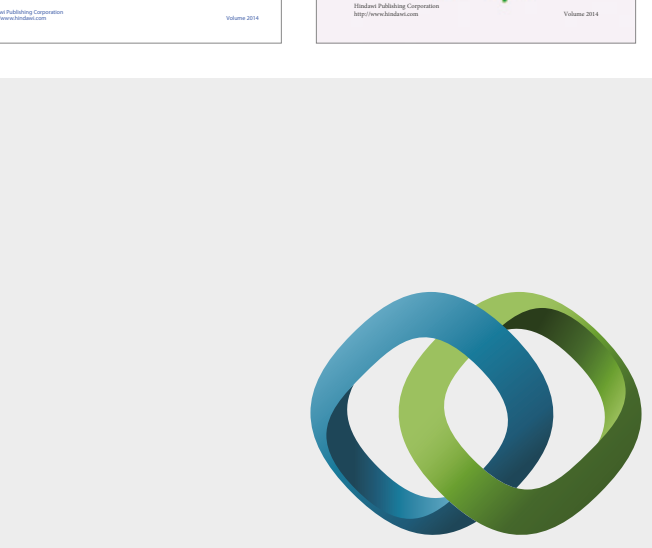

\section{Hindawi}

Submit your manuscripts at

https://www.hindawi.com
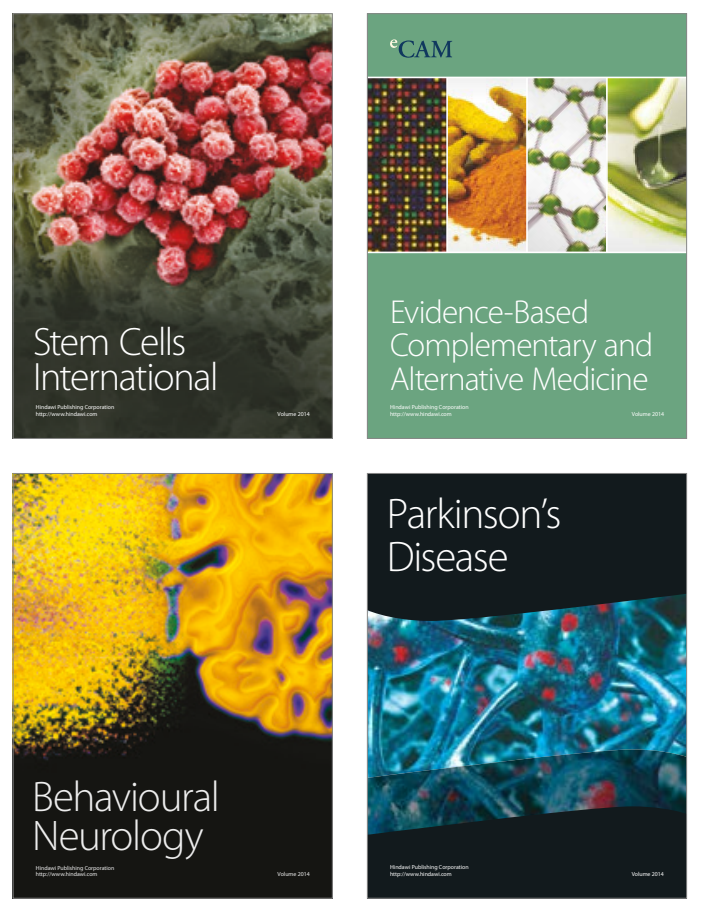
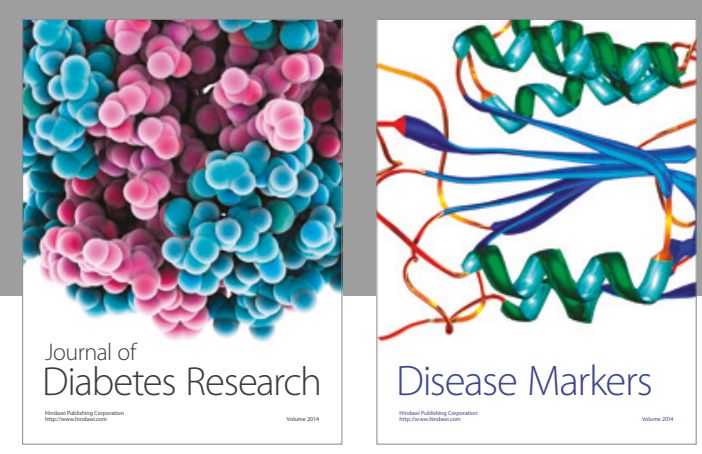

Disease Markers
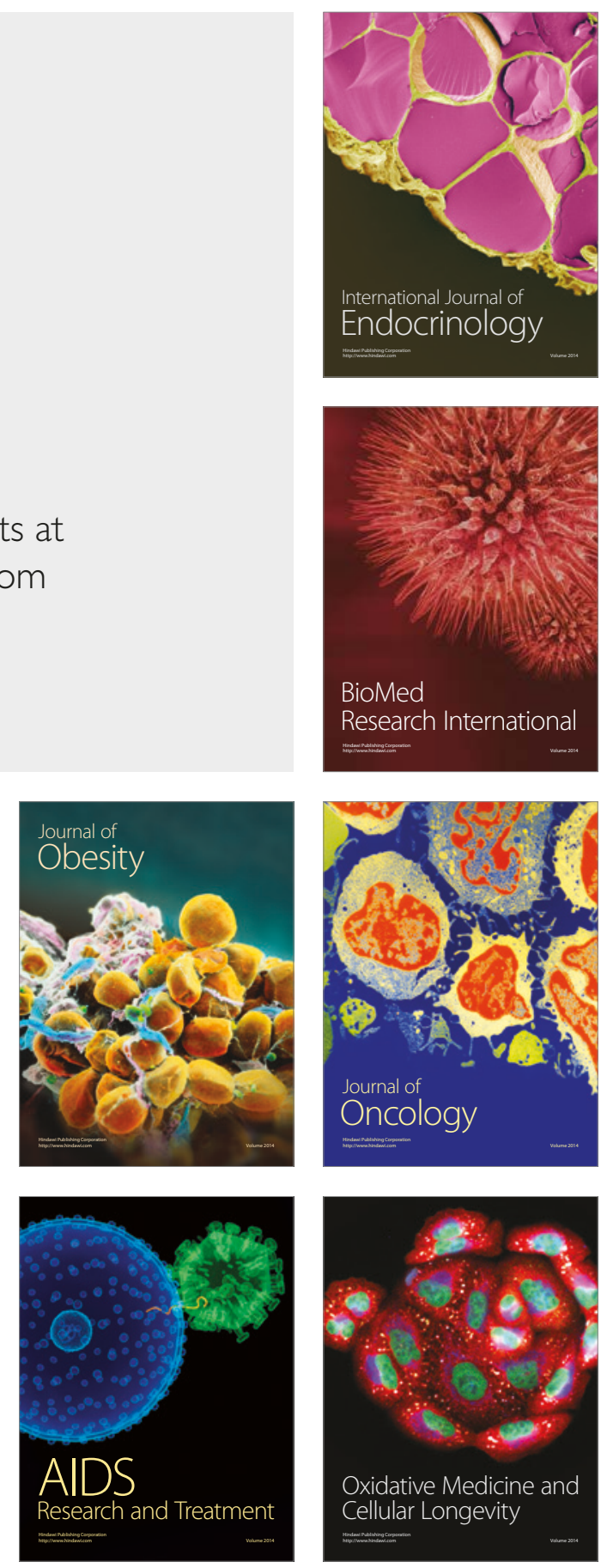